\title{
Objective Measures of Spatial Effects in Spanish Concert Halls
}

\author{
Sara GIRÓN ${ }^{(1)}$, Teófilo ZAMARREÑO ${ }^{(1)}$, Pedro BUSTAMANTE ${ }^{(2)}$ \\ (1) Departamento de Física Aplicada II Universidad de Sevilla, E.T.S. Arquitectura (IUACC) \\ Av. Reina Mercedes 2, 41012-Sevilla, Spain; e-mail: \{sgiron, teofilo\}@us.es \\ (2) Departamento de Construcciones Arquitectónicas I, Universidad de Sevilla, E.T.S. Arquitectura (IUACC) \\ Av. Reina Mercedes 2, 41012-Sevilla, Spain; e-mail: bustamante@us.es
}

(received April 9, 2012; accepted October 22, 2012)

\begin{abstract}
The present work consists of a statistical study of the monaural (lateral-reflection fractions and level) and binaural acoustic parameters (inter-aural cross-correlation coefficients) that evaluate the amount of early and late lateral acoustic energy encountered in 9 performance halls in Andalusia (southern Spain). Hall volumes range between $6,163 \mathrm{~m}^{3}$ and $34,594 \mathrm{~m}^{3}$ and all enclosures are used for presentations of symphonic concerts and other music performances. The majority of these venues are located in provincial capitals of the community and often constitute the only premises in the city where symphonic concerts can be held. The acoustic parameters under study here were derived from impulse responses analyses using a sine-sweep signals which were generated and processed by WinMLS 2004 software in the octaveband frequency centred from 125 to $4 \mathrm{kHz}$, and all parameters were spectrally averaged according to the ISO 3382-1 standard. A comparison is presented of monaural experimental results as a function of sourcereceiver distance with the prediction of Barron's revised theory for concert halls, and the analyses of the acoustic parameter results are carried out in terms of their respective just noticeable differences: at the many microphone positions for the two source positions on stage, for the spatial distribution of seats in the audience zone relative to the central axis (for left- and right-hand sides) of the rooms, and for the presence of the orchestra shell on stage. Results reveal that the orchestra shell propitiates a perceptible decrement in the values of the early lateral energy fraction and an increment in the late lateral level at the audience seats. In addition, a regression study reveals that the two kinds of measures of laterality, monaural and binaural, are correlated when the hall-average data is considered, but they remain uncorrelated when all individual positions are used. Likewise, the ranges of variation of the acoustic parameters found in these halls are narrower than those specified in the ISO 3382-1. The paper concludes with a discussion on the relationships of hall-average data of the five parameters with eight geometric and acoustic variables.
\end{abstract}

Keywords: concert hall acoustics, directional energy parameters, binaural parameters, spatial impression, spatial effects.

\section{Introduction}

After the commencement of the science of architectural acoustics with W. C. Sabine's contributions in 1895 (SABINE, 1993), breakthroughs and rapid development of electroacoustics in the first half of the twentieth century propitiated a great advance in general acoustics. However, it is from the last third of the last century that the science of room acoustics experienced a resurgence propelled by the emergent computer and signal science. As a consequence of research in that new age, considerations other than those in the monaural temporal factors came into play beyond the scope of reverberation time to determine optimal configurations for listening spaces (BERANEK, 1962). In the 1960s, the first references appeared (SCHROEDER et al., 1966; MARSHALL, 1967) that considered the significance of spatial effects in the acoustics of concert halls. This perception refers to how the acoustical impression in a room differs from that which lacks many delayed reflections arriving from all directions. Soon after, work by MARSHALL (1968), and BARRON (1971) confirmed that this impression is produced by the early lateral reflections, and this understanding has since had a significant impact on concert hall design (CREMER, 1989; BERANEK, 1992). As a typical spatial factor of the sound field, DAMASKE and ANDo (1972) defined the interaural cross-correlation coefficient, and in a refined 
approach, ANDo (2007) developed a theory of subjective preferences in relation to temporal and spatial factors of the sound fields based on the modelling of the human auditory-brain system (SoETA et al., 2002).

Rooms for music are the most visible and interesting spaces in architectural acoustics where the three disciplines, of acoustics, architecture and music are blended. However, rating the acoustic quality of a hall for musical performances is a non trivial and multidimensional topic due to the lack of an unequivocal criterion of listeners' music appreciation, in contrast to that for the one-dimensional comprehension of speech (PEuTZ, 1971).

Spatial impression phenomenon is a general term which covers two subjective perceptual categories: apparent source width (ASW), and listener envelopment (LEV). ASW is the apparent auditory width of the sound field created by a performing entity as perceived by a listener in the audience area of a concert hall, and experiments have concluded that it is mainly related to the early lateral reflections reaching the listener (BARRON, 1971). LEV is considered as the subjective impression by a listener of being enveloped by the sound field: a condition that is, according to experiments, primarily related to the late lateral sound field (BRADLEY et al., 2000).

Two types of measurements of lateral reflections from the impulse response in a room have emerged: the monaural lateral energy fractions $(J)$ related to the energy of early or late lateral reflections in the former case, and the interaural cross-correlation coefficient (IACC) in the latter, which is a measure of the difference in sound at the two ears and hence of laterality.

To assess ASW, the early lateral energy fraction $J_{L F}$ (BARRon, MARShall, 1981), (or alternatively, the early lateral energy fraction cosine $J_{L F C}$ (KLEINER, 1989), is accepted as a monaural directionally influenced measure. Likewise, the normalised interaural cross-correlation function IACF (DAMASKE, ANDO, 1972) is a measure of the dissimilarity between the arrivals of the wave at the two ears. From this function the interaural cross-correlation coefficients, IACC, are then given by:

$\mathrm{IACC}_{t_{1}, t_{2}}=\max \mathrm{IACF}_{t_{1}, t_{2}}$ for $-1 \mathrm{~ms}<\tau<+1 \mathrm{~ms}$. In which $t_{1}=0$ and $t_{2}=80 \mathrm{~ms}$ (subscript $E$ ) are chosen for the early interaural cross-correlation coefficient $\mathrm{IACC}_{E}$ which assesses the ASW perceptual attribute (HidAKA et al., 1995; OKANO et al., 1998).

In the same way, the late lateral sound level $L_{J}$ is proposed as a standard (Bradley, Soulodre, 1995a; 1995b) in the monaural impulse response measurement in order to provide a practical indicator of the amount of listener envelopment in concert halls for sound arriving from all directions (EvJEN et al., 2001), and the late interaural cross-correlation coefficient $\mathrm{IACC}_{L}$ (correlation calculated from $t_{1}=80 \mathrm{~ms}$ to infinity (subscript $L$ )) in the binaural measurement, is pro- posed by Hidaka et al. (1995), and OKANO et al., (1998).

Alternatively, a further parameter which involves a ratio, the late lateral energy fraction $J_{L L F}$, (BARRON, 2001) defined by the same ratio as $J_{L F}$ but for the late interval, to study listener involvement is also considered here. Both monaural late lateral parameters are related to omnidirectional sound strength $G$ and clarity parameter $C_{80}$ through:

$$
J_{L L F}=10^{\left(L_{J}-G\right) / 10}\left(1+10^{C_{80} / 10}\right) .
$$

Due to the contamination of the results with background noise under certain frequencies, this parameter cannot be obtained directly from WinMLS, and hence its calculation in this work is as defined above.

According to several experiments, the spectral content of lateral reflections that contribute towards the ASW and LEV and lateral levels in the monaural parameters are in the four octave bands with centre frequencies 125, 250, 500, and $1000 \mathrm{~Hz}$ (HidAKA et al., 1995), respectively. This measure favours the frequency region where the wavelengths are mostly longer than the acoustical distance between the left- and righthand sides of a head. In the case of the IACC parameter, no widespread agreement yet exists on how to calculate averages over various octave bands: in fact ISO 3382-1:2009(E) (2009) does not specify this point. Throughout this work the spectral average of the IACC parameter is determined following Hidaka's instructions (HIDAKA et al., 1995; OKANO et al., 1998), which are based on previous experiments of BLAUERT and Lindemann (1986a, 1986b) and which concludes that $500,1 \mathrm{k}$, and $2 \mathrm{kHz}$ are the octave bands of equal and principal importance for the ASW attribute covering the effect on spatial impression categories of the entire octave band frequency range (OKANO et al., 1998). Henceforward, these experimental measures obtained by arithmetically averaging within these respective aforementioned frequencies are named $J_{L F m}$, $J_{L F C m}, J_{L L F m}, \mathrm{IACC}_{E m}$, and $\mathrm{IACC}_{L m}$, respectively. According to international standards (ISO, 2009) the frequency-averaged late lateral sound energy level, $L_{J m}$ must be averaged in energy.

Although De VRIES et al. (2001) suggested a decomposition of the measures to suppress interference effects to which the human ear is apparently insensitive, the revised ISO standard (ISO, 2009) has proposed $J_{L F m}, J_{L F C m}$ as objective measurements of the perceptual listener aspect ASW, a just-noticeable difference of 0.05 , and a typical range of values from 0.05 up to 0.35 (frequency-averaged values in single positions in non-occupied concert and multi-purpose halls up to $25,000 \mathrm{~m}^{3}$ ). For $L_{J m}$, its just-noticeable difference remains unknown and for IACC according to Cox et al. (1993) a just-noticeable difference of 0.075 is assumed. 
Within this field, other pieces of work (MоRIмото et al., 2008) have proposed experiments to clarify the essentials of ASW and LEV from the point of view of auditory behaviour by suggesting that the acoustic components of the reflections over and beyond the upper limit of the precedence effect contribute towards ASW and LEV, respectively. Furthermore, the components from behind the listener generate greater LEV (Morimoto et al., 2001). AbDou and Guy (1996) also pointed out the necessity of spatial information on the sound fields for the evaluation of the acoustics of rooms and the diagnosis and correction of the causes of acoustic defects.

This paper aims to interpret and discuss the results of monaural and binaural measures of spatial impression in 9 performance spaces of southern Spain which are used as concert halls and for other musical performances. Analyses are carried out in terms of seat positions and hall-average values with significant physical variables of the acoustic field. The spatial distribution of the various parameters, the differences found due to the two source positions on the stage, and to the orchestra shell are analysed in terms of their respective just-noticeable differences (JND). These analyses could provide a starting point for further studies of correlation between objective parameters and spatial impression.

\section{Experimental method}

\subsection{Measurement technique}

The procedures employed here are those established in the ISO 3382-1 standard (ISO, 2009), whereby measurements were carried out in unoccupied rooms and on unoccupied stages (no public, no musicians), safety curtains were always drawn open, and, in certain cases with the orchestra shell configuration in the stage, chairs and music stands were present. Temperature and relative humidity were monitored during the measurements which revealed a range of variation of the environmental conditions during measurements in all enclosures of $16.8-25.2^{\circ} \mathrm{C}$ for the temperature, and $38-60 \%$ for the relative humidity, respectively, with the exception of Falla Grand Theatre which was measured in winter, whose minimum temperature was $14.1^{\circ} \mathrm{C}$. The variations between the environmental conditions for the halls that have been measured with and without an orchestra shell in the stages never exceeded $1^{\circ} \mathrm{C}$ in temperature and $8.5 \%$ in relative humidity respectively, except for Falla Grand Theatre whose measurements were carried out in winter and spring with a difference of $9^{\circ} \mathrm{C}$ in temperature and $12 \%$ in relative humidity, respectively.

Monaural and binaural impulse responses (IRs) were measured to determine, among others, the following parameters for each frequency band between $125 \mathrm{~Hz}$ to $4000 \mathrm{~Hz}$ and in all receiver positions: the early lateral energy fraction $\left(J_{L F}\right)$ and early lateral energy fraction cosine $\left(J_{L F C}\right)$, the late lateral fraction $\left(J_{L L F}\right)$, the late lateral level $\left(L_{J}\right)$, and the binaural interaural cross-correlation coefficients (IACC), to study the spatial impression phenomena in the rooms.

The IR has been obtained at each reception point using sine sweep signals which were generated and analysed by WinMLS 2004 software via the VX Pocket v2 sound card from Digigram. The omnidirectional dodecahedral source DO12 with its InterM-1000 amplifier, is placed at the most usual point of location of the natural source (S) on the orchestra platform (none in the orchestra pit which was always covered with wooden panels or heavy curtains) at a height of $1.50 \mathrm{~m}$ from the floor. Wherever possible, measurements in two source positions on the stage have been carried out (see Table 1 and Fig. 1). In all cases the S1 position coincides with the central source position on the stage; and these two source locations coincide for the configurations with and without an orchestra shell. Two microphones have been used: multipattern configurable Audio-Technica AT4050/CM5 (with an appropriate signal-conditioning Earthworks LAB1 amplifier) to measure lateral energy fractions and levels; and a torso type HSU III simulator (Code 1323) from Head Acoustic (with OPUS amplifier) to record binaural IR. They are all located at the approximate height of the head of a seated person, $\sim 1.20 \mathrm{~m}$ from the floor, in a predetermined number of seats within the various audience zones (these seats are coincident for the measurements carried out with and without the orchestra shell on the stage in certain halls).

\subsection{The halls researched}

In this section, data for the 9 concert halls under research is presented: Cordoba Grand Theatre (CGT), located in Cordoba; Falla Grand Theatre (FGT), located in Cadiz; Huelva Grand Theatre (HGT), located in Huelva; Isabel la Católica Theatre (ICT), located in Granada; Lope de Vega Theatre (LVT), located in Seville; Miguel de Cervantes Theatre (MCT), located in Malaga; Manuel de Falla Auditorium (MFA), located in Granada; Maestranza Theatre (MT), located in Seville; and Villamarta Theatre (VT), located in Jerez de la Frontera (Cadiz). They appear in alphabetical order in accordance with the acronyms assigned from their names on the MIREM web site (digital scenic and musical enclosure map of Spain), where further information on the enclosures is available (MIREM, 2012). Details on the stage shell of these spaces and stage support parameters have been published elsewhere (GIRón et al., 2010).

In all these buildings, several types of cultural activities, such as opera, theatre, dancing, cinema and concerts, may be performed, except in the Manuel de Falla Auditorium where only concerts and recitals are presented. These are performance spaces with a fixed 
public-stage relationship and a frontal description, except the Manuel de Falla Auditorium which presents a bi-frontal description, (it consists of two rooms $\mathrm{A}$ and B, see Fig. 1). It is also pertinent to add that all 7 proscenium theatres were refurbished by the regional government during the 1980s and 1990s, and that acoustic measures have been carried out after these refurbishments.

In Table 1, the year of completion or inauguration, architectural type, the number of floors, the number of points of reception for the microphones, and the seat capacity are all summarized in alphabetical order, together with the most relevant architectural and acoustical dimensions (LEÓN et al., 2007), whose calculations are described below.

Mean width $W$ : for horseshoe-shaped halls this is the maximum width on the ground floor excluding boxes; if it is rectangular but irregular, then a mean value is taken as in ICT; in the case of MFA, this geo- metrical factor excludes boxes at both sides of room A; and in MT this is its transverse diameter.

Mean height $H$ : calculated as the average of the height of the room in the mouth of the stage, in the middle, and at the rear of the hall.

Mean depth $D$ : the average of the horizontal measure that exists from the stage to the back of the room on all floors. (In the case of MFA, it is the length of room A).

Audience surface $S_{A}$ : the area occupied by all seats in the hall.

Total volume $V$ : hall and stage volume (in the two configurations if it exists with and without the orchestra shell).

Reverberation time $\mathrm{T}$ : the reverberation time measured in the unoccupied halls and averaged spatially and spectrally in the 500 and $1000 \mathrm{~Hz}$ octave bands.

Absorption $A$ : the absorption obtained using the reverberation time in Sabine's formula.
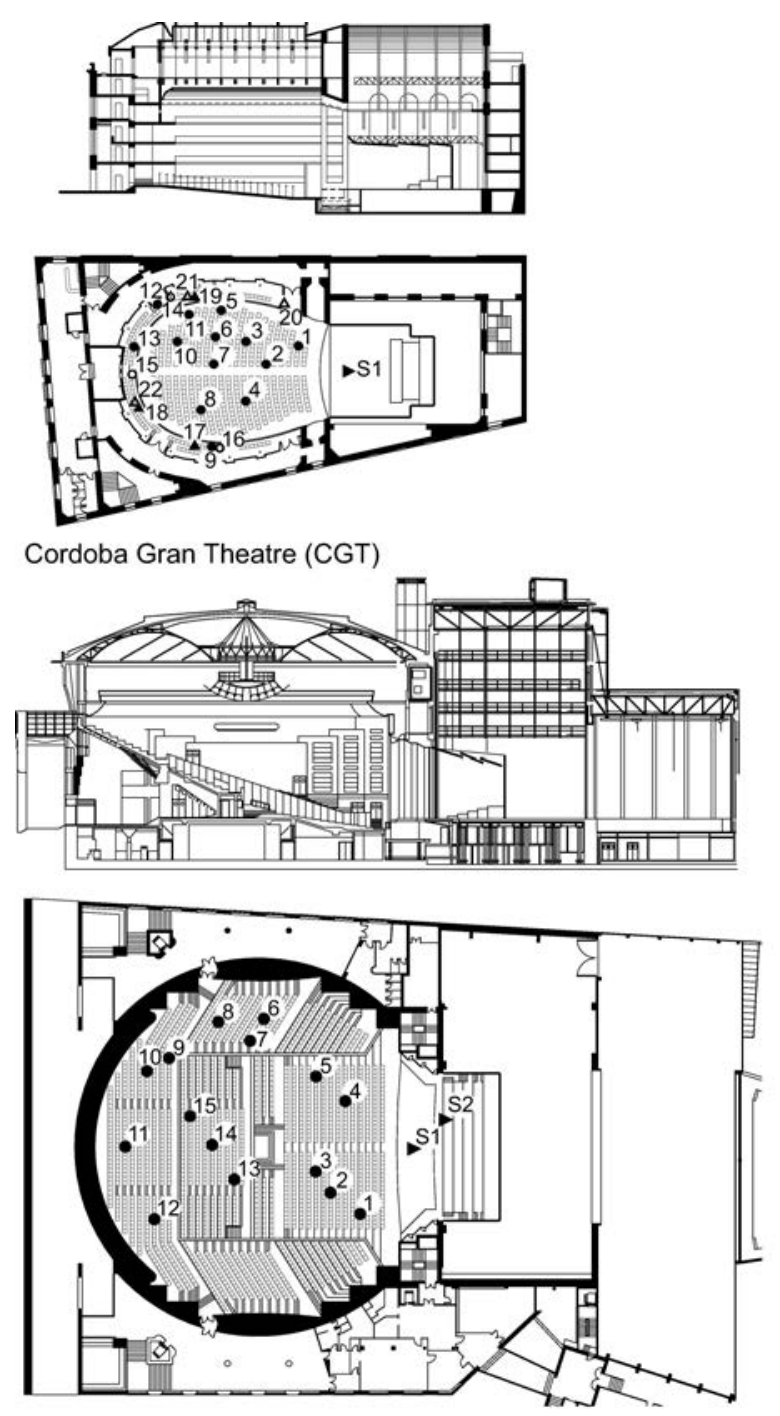

Maestranza Theatre (MT)
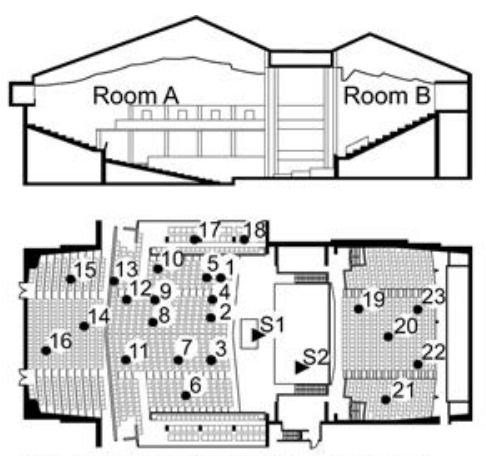

Manuel de Falla Auditorium (MFA)
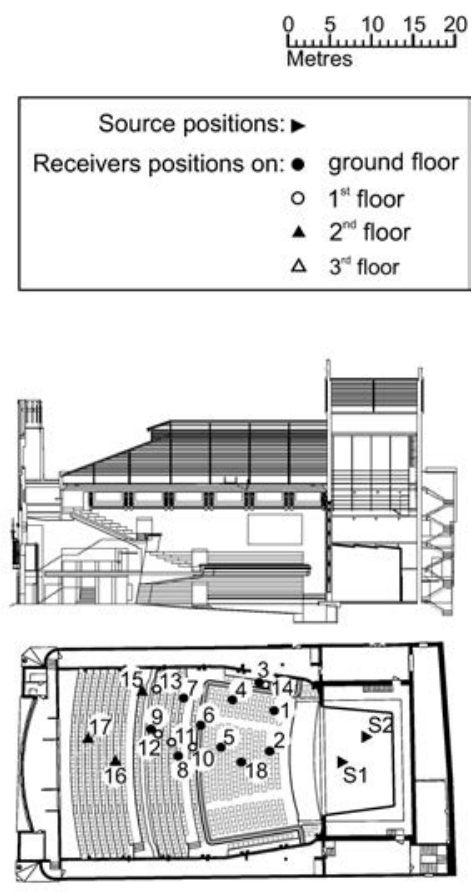

Villamarta Theatre (VT)

Fig. 1. Ground plan and longitudinal section of 4 halls of the total spaces analysed. The positions of the source and the reception points on each floor are also shown. 
Table 1. Relevant data of the concert halls studied.

\begin{tabular}{|c|c|c|c|c|c|c|c|c|c|c|}
\hline \multicolumn{2}{|l|}{ Hall } & CGT & FGT & HGT & ICT & LVT & MCT & MFA & MT & VT \\
\hline \multicolumn{2}{|c|}{ Year of completion } & 1873 & 1910 & 1923 & 1952 & 1929 & 1870 & 1978 & 1991 & 1928 \\
\hline \multicolumn{2}{|c|}{ Typology $^{a}$} & $\mathrm{HP}$ & HP & SP & SP & HP & $\mathrm{HP}$ & $\mathrm{RA}$ & $\mathrm{CA}$ & $\mathrm{SP}$ \\
\hline \multicolumn{2}{|c|}{ Number of seats $N$} & 946 & 1038 & 601 & 689 & 733 & 1058 & $\begin{array}{l}\text { A: } 890 \\
\text { B: } 413\end{array}$ & 1800 & 1200 \\
\hline \multicolumn{2}{|c|}{ Hall volume $\left[\mathrm{m}^{3}\right]$} & 6071 & 8114 & 4800 & 5035 & 5902 & 6594 & $\begin{array}{l}\text { A: } 4274 \\
\text { B: } 1536\end{array}$ & 20321 & 7988 \\
\hline \multicolumn{2}{|c|}{ Number of floors } & 4 & 4 & 4 & 3 & 4 & 4 & 1 & 1 & 3 \\
\hline \multicolumn{2}{|c|}{ Stage volume no shell $\left[\mathrm{m}^{3}\right]$} & 4631 & 5556 & 1963 & 1742 & 3363 & 4907 & 3421 & 14273 & 3703 \\
\hline \multicolumn{2}{|c|}{ Stage volume with shell $\left[\mathrm{m}^{3}\right]$} & 872 & 1728 & - & - & - & 945 & - & 1850 & $574+405$ \\
\hline \multicolumn{2}{|c|}{ Total volume ${ }^{b}\left[\mathrm{~m}^{3}\right]$ no shell $V^{\prime}$} & 10702 & 13670 & 6763 & 6777 & 9265 & 13873 & $9231^{c}$ & 34594 & 11691 \\
\hline \multicolumn{2}{|c|}{ Total volume ${ }^{b}\left[\mathrm{~m}^{3}\right]$ with shell $V$} & 6943 & 9842 & - & - & - & 9911 & - & 22171 & 8562 \\
\hline \multicolumn{2}{|c|}{ Hall mean width, $W[\mathrm{~m}]$} & 17.0 & 17.7 & 10.4 & 18.0 & 16.6 & 17.7 & $\mathrm{~A}+\mathrm{B}: 19.7$ & 37.0 & 22.8 \\
\hline \multicolumn{2}{|c|}{ Hall max depth, $D[\mathrm{~m}]$} & 25.3 & 25.6 & 17.4 & 21.9 & 27.1 & 23.3 & $\mathrm{~A}+\mathrm{B}: 24.4$ & 36.3 & 24.9 \\
\hline \multicolumn{2}{|c|}{ Hall mean height, $H[\mathrm{~m}]$} & 12.4 & 14.9 & 16.7 & 17.3 & 18.9 & 19.9 & $\mathrm{~A}+\mathrm{B}: 11.1$ & 14.3 & 14.9 \\
\hline \multicolumn{2}{|c|}{ Seat surface, $S_{A}\left[\mathrm{~m}^{2}\right]$} & 536 & 687 & 354 & 449 & 411 & 699 & $\mathrm{~A}+\mathrm{B}: 786$ & 1156 & 555 \\
\hline \multirow{2}{*}{ R. points } & no shell & 22 & 15 & 16 & $12 / 12$ & $14 / 14$ & 15 & $22 / 22$ & - & $18 / 18$ \\
\hline & with shell & 17 & $15 / 15$ & - & - & - & $15 / 15$ & - & $15 / 15$ & 17 \\
\hline \multirow{2}{*}{$T[\mathrm{~s}]$} & no shell & 1.17 & 1.89 & 1.41 & 1.26 & 1.44 & 1.26 & 2.33 & - & 1.85 \\
\hline & with shell & 1.19 & 1.86 & - & - & - & 1.14 & - & 2.51 & 1.70 \\
\hline \multirow{2}{*}{$A\left[\mathrm{~m}^{2}\right]$} & no shell & 1473 & 1165 & 772 & 866 & 1036 & 1773 & 638 & - & 1017 \\
\hline & with shell & 939 & 852 & - & - & - & 1400 & - & 1422 & 811 \\
\hline
\end{tabular}

${ }^{a} \mathrm{HP}-$ Horseshoe proscenium floor plan. SP - Shoebox proscenium floor plan. RA - Rectangular auditorium floor plan. $\mathrm{CA}-$ Cylindrical auditorium floor plan. ${ }^{b}$ Hall and stage volumes. ${ }^{c}$ Halls A and B plus stage.

To complete this information and to avoid excessive length, Fig. 1 shows the plotted graphs of the ground plans and longitudinal section of only the CGT, MFA, MT, and VT, respectively. The plans include the points of reception on each floor in the theatres with different symbols, and the two positions of the source on the stage. In addition, Fig. 2 shows a set of photographs of the interiors of each hall taken from their stage, and from room B in the case of MFA.
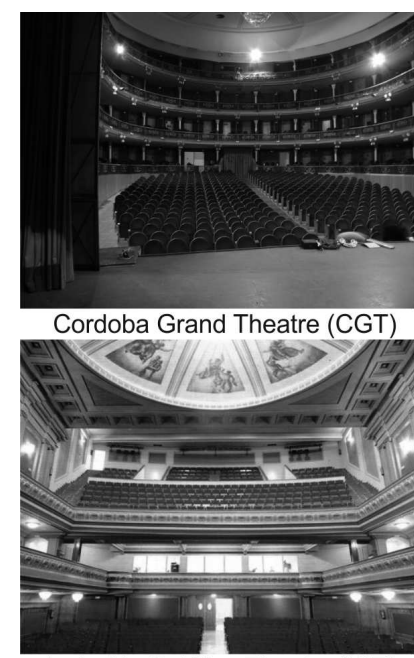

Isabel la Católica Theatre (ICT)

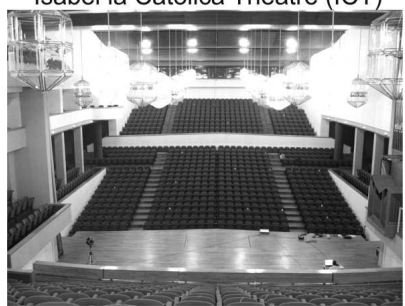

Manuel de Falla Auditorium (MFA)

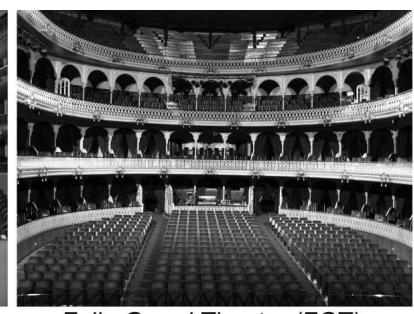

Falla Grand Theatre (FGT)

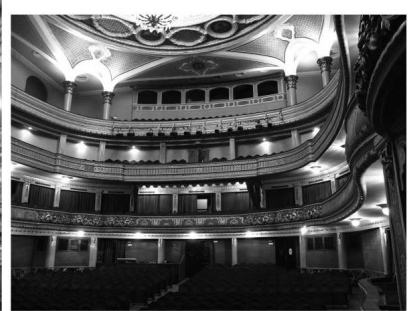

Lope de Vega Theatre (LVT)

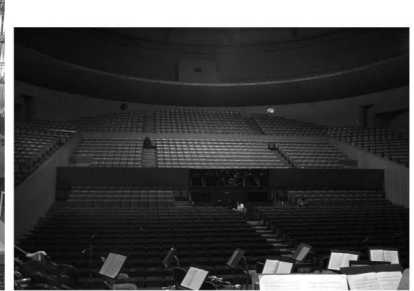

Maestranza Theatre (MT)

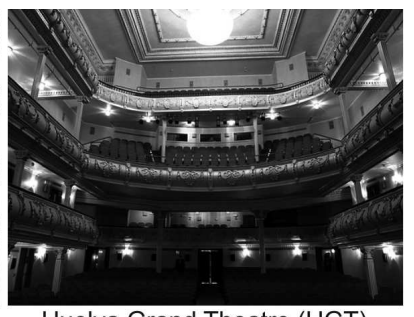

Huelva Grand Theatre (HGT)

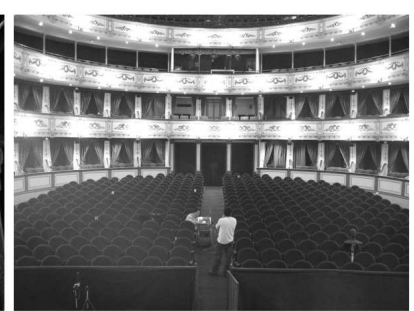

Miguel de Cervantes Theatre (MCT)

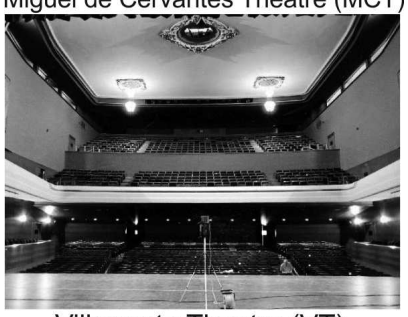

Villamarta Theatre (VT)

Fig. 2. Views from the stage of the interiors of the halls; for MFA the view is from room B. 


\section{Analyses of experimental results and discussions}

This section covers, in its various subsections, the analyses of monaural and binaural parameters studied in the 9 concert venues, both in terms of their spatial values in the spaces as well as in terms of the relationships between the different types of parameters that evaluate the same perceptual attributes of spatial impression. The correlations between the hallaverage parameters with the geometric and acoustic parameters of the halls are also carried out. In all cases, the analyses presented refer to the results of the spectral averages of the parameters as stated at the end of Sec. 1. These results can be used to further studies of correlation between objective parameters and spatial impression.

As a starting point, a comparison by regression of the experimental values of the two monaural early lateral fractions, $J_{L F m}$ and $J_{L F C m}$, is carried out. Regression analysis shows that the two parameters are linearly related when the results are compared for each hall and include the results of the two stage configurations, and when the results are studied in all individual positions in all the halls together. In the former case the weakest correlation is, for FGT without the orchestra shell:

$$
\begin{aligned}
& J_{L F C m}=0.569 J_{L F m}+0.132, \\
& R^{2}=0.6144, \quad P=0.0005,
\end{aligned}
$$

and the strongest linear correlation also for FGT, but with the shell:

$$
\begin{aligned}
& J_{L F C m}=0.785 J_{L F m}+0.104, \\
& R^{2}=0.9560, \quad P<0.0001 .
\end{aligned}
$$

By considering the results in all individual positions for all halls (321 pairs of values, for the two configurations of the stage and the two source positions) the best fit corresponds to a straight line:

$$
\begin{gathered}
J_{L F C m}=0.837 J_{L F m}+0.091, \\
R^{2}=0.8554, \quad P<0.0001 .
\end{gathered}
$$

The good results of statistical analysis indicate that these two parameters are very similar and that the experimental procedure is correct and can therefore be used alternately for either directional parameter of early lateral energy. Similar results have been obtained with different equipment in worship spaces of a common typology (GIRón et al., 2008). Henceforward, the results of $J_{L F m}$ are used since this parameter presents the best facilities for measuring and has experienced the widest use in other experimental work, thereby facilitating comparison.

\subsection{Spatial distribution of the lateral acoustic parameters. Effect of the orchestra shell}

As a first step of this analysis, all the parameters were studied as a function of source-receiver distance. In general, the empirical data set appears as a cloud of points and fails to indicate any predictable behaviour in terms of source-receiver distance. Furthermore, for the two possible stage configurations, these experimental results were also compared with the theoretical values determined by Barron's revised theory of sound propagation in halls (BARRON, LEE, 1988), where reverberation time $T$, (measured in the unoccupied halls and averaged spatially and spectrally in the 500 and $1000 \mathrm{~Hz}$ octave bands), and the total volume $V$, are the only magnitudes involved in their calculations.

In order to avoid excessive length, the detailed results of this study are not shown. However, its main conclusions can be summarized as: A) There is considerable scatter from the theoretical predictions and the furthest deviations generally occur in the late lateral level $L_{J m}$ regardless of the type of hall and of the source-receiver distance. B) The influence of the orchestral shell on the stage in the theoretical predictions is very small. In the experimental results the differences are small, similar to the findings obtained by BRADLEY (1996), but perceptible (in terms of JND), as will be analysed later. C) Barron's revised theory of sound propagation in halls indicates that late lateral sound levels are more sensitive to changes in reverberation time and room volume than early lateral fractions (BARRON, 2001), and hence the effect of adding an orchestra shell may be the greatest on the late lateral arriving sound levels at audience seat locations.

In the absence of predictable behaviour when studying the results of these five parameters versus distance to the source on the stage, it was decided to conduct a study of their spatial distribution by following a common methodology for the five parameters studied. This consists of evaluating the parameters according to distances from the points of reception to the central axis of the room, $x$ (for left- and right-hand sides), and by normalizing these distances with respect to half the average width of each room, $w$, then these relative distances are presented as $(x / w)$. This method of evaluation is justified by the fact that spatial impression is related to the presence of early and late lateral reflections, and that the closer the walls, the higher intensity should be.

For the analysis of this comprehensive spatial distribution in all rooms, the values of the acoustic parameters related to spatial impression are grouped into discrete intervals of the aforementioned relative distances $(x / w)$. The magnitude of these intervals is set at 0.25 , where positions $x / w>1$ express the positions of the microphone very close to the side walls, which in all cases correspond to positions in areas of boxes and 
side terraces on the ground or upper floors and therefore usually under an overhang, (e.g. in CGT, FGT, HGT, LVT, MCT and MFA). It should be borne in mind that all the parameters studied at each position have been averaged in frequency at the octave bands, with the procedures established by ISO 3382-1 (ISO, 2009), listed in Sec. 1.

On the other hand, in small cities, it is very common to adapt performance halls to the needs of orchestral music by means of orchestra shells. Despite their widespread use, very little published information exists on their acoustical properties and their influence in the acoustic field of the hall. This section also analyses the influence of shells on the parameters considered in the different areas.

\subsubsection{Early lateral energy fraction $J_{L F m}$}

In Fig. 3a, the early lateral energy monaural parameter $J_{L F m}$ is plotted in ordinates and scaled at intervals of 1 JND. In abscissa, the relative distance to the central axis of the room is given for all the halls studied without the orchestra shell and with results for the two positions of the sound source (S1 and S2 on the stage, in the drawings of Fig. 1). The number of measurement points in each discrete positional zone is also specified at the top of the graph. The typical range for this parameter (expressed in Fig. 3a as ISO) according to ISO 3382-1 (ISO, 2009), is $(0.05,0.35$ ) for non-occupied concert halls and multi-purpose halls with a volume of less than $25,000 \mathrm{~m}^{3}$. Figure 3 a also indicates another narrower range found in these performance spaces $(0.10,0.30)$ which means a cut of 1 JND in both the upper and lower limits of the range with respect to those specified in ISO 3382-1. It can be observed that this range includes, in each case, the vast majority of experimental results. The criterion used in their specific determination according to Fig. 3b, is discussed later.

The filled symbols linked by lines show the average values of the $J_{L F m}$ parameter in each positional inter$\mathrm{val}$, and the degree of spatial dispersion in each interval is characterized by the standard deviation (vertical bars). The spatial dispersion tends to increase slightly for positions closer to the side walls $x / w>1$ and the analysis of the results indicates that, for $x / w$ between 0.25 and 0.75 , the average values of the parameter are very constant and only for the area near the centre of the halls, $x / w<0.25$, does $J_{L F m}$ reduce its values by 0.5 JND.

As a complement to Fig. 3a, and in order to normalize the experimental data with respect to the spatial distribution in the areas concerned, Fig. 3b expresses in ordinates the percentage of the experimental data in each interval of 1 JND $(n)$ for values of $J_{L F m}$ in each positional area $(x / w)$ in relation to the total data in the same area, named $n_{\Delta(x / w)}$ (see top of Fig. 3a). a)

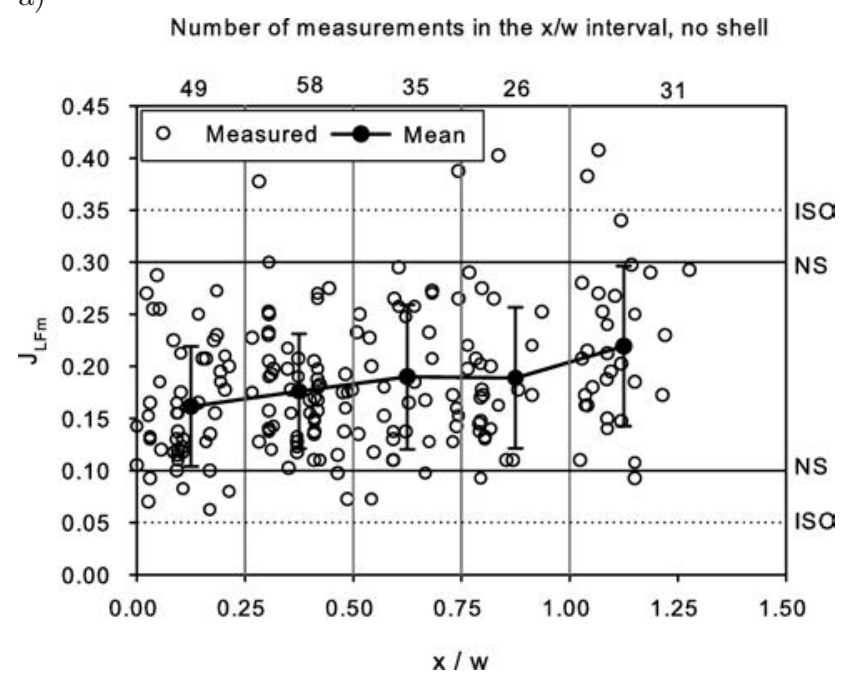

b)

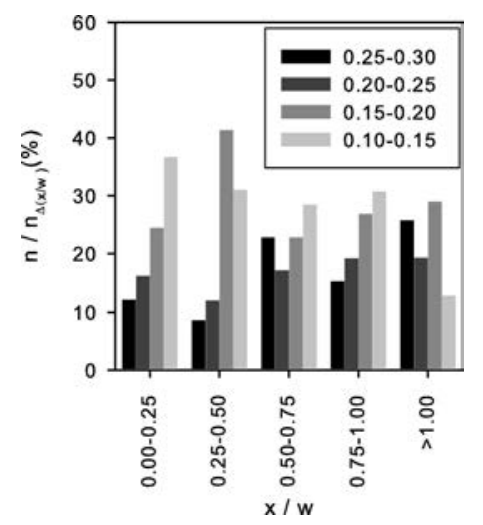

Fig. 3. a) Early lateral energy fractions in the relative distance intervals to the central axis of the halls, for all halls, for the two source positions and for the without shell on the stage. The mean values and their standard deviations for each interval are also shown. The typical range of values in this work and in ISO 3382-1 are presented; b) fraction of data for values of $J_{L F m}$ in steps of 1 JND in the different intervals of $x / w$ relative to the total number of data in each interval corresponding to the results shown in part (a).

It can be seen that for each interval the total sum fails to reach $100 \%$, the reason being that only those values of the acoustic parameter for which the data lies mostly above $10 \%$ in the whole range variation were considered as significant in the two figures. Residual values correspond to the range of variation of $J_{L F m}$ between $(0.00,0.10)$ in the lower range and $(0.30,0.45)$ in the top range. This determines the typical range of parameter variation in these rooms. In this distribution, it can be observed how the percentage for the two major ranges (black and dark grey bars) increments when approaching the lateral walls.

In order to discern the effect of the orchestral shell on the behaviour of the parameter, Fig. 4a shows a similar study of $J_{L F m}$ but considering only the four performance halls (CGT, FGT, MCT, and VT) which 
a)

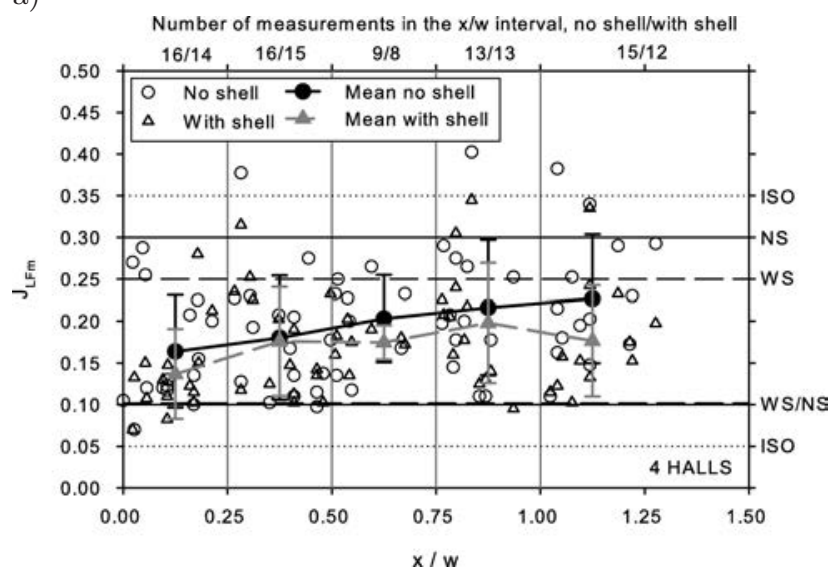

b)

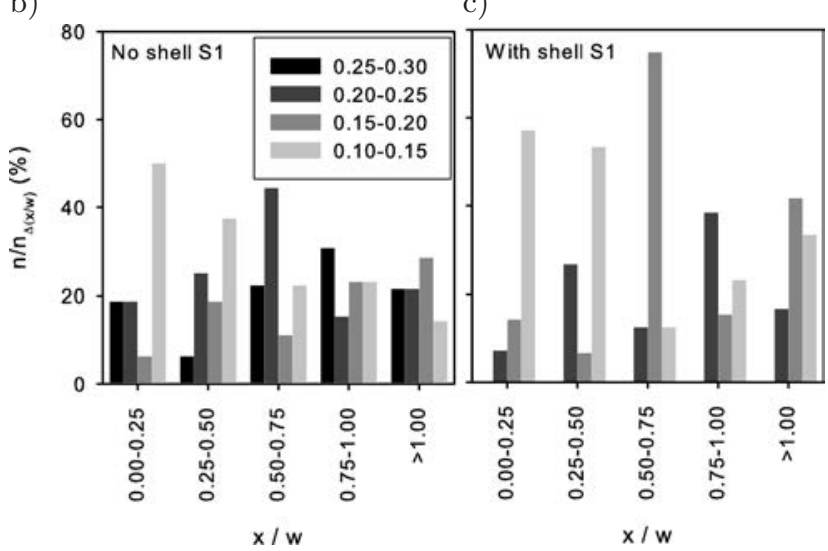

Fig. 4. a) Early lateral energy fractions in terms of the different intervals of relative distance to the central axis for 4 halls, at S1 source position and for the two stage configurations. The mean values and their standard deviations for each interval and the typical range of values in this work (with shell and no shell) and in ISO 3382-1, are also shown; b) fraction of data for values of $J_{L F m}$ in steps of $1 \mathrm{JND}$ in different intervals of $x / w$ relative to the total amount of data in the same interval, for 4 halls without the orchestra shell; c) idem with the orchestra shell on the stage.

have been studied with the two configurations of the stage and solely at the source position S1, to ensure compatible data in the two configurations. The study thus shows the possible effect when the amendment of only one variable is involved (the shell). (Although the amount of data should coincide, there remains a slight difference due to technical problems that arose in one space (CGT), see the top of Fig. 4a).

Results confirm the trend obtained for the withoutshell configurations that were studied for all halls in Fig. 3a, and the maintenance of the range established $(0.10,0.30)$ for both statistical populations of data (thereby validating statistical results for the with-shell configuration), and also show that shells lead to a significant decrease in the average values of the parameter $J_{L F m}$ in all audience zones. Specifically, in the centre of the stalls, $x / w \in(0.00,0.25)$, while between 0.50 and
0.75, the decrease is about 0.5 JND. For the zone of boxes and upper balconies under overhangs, the order of the decrease is 1 JND. This suggests, at least initially, that shells focus sound by decreasing the initial lateral reflections, especially in the areas under balconies.

In addition, spatial dispersion presents similar behaviour remaining very similar in the other areas and reaches its highest value, at $x / w>1$, the area near the side walls.

Results also confirm the narrower range deduced before for the no-shell configuration in this parameter $(0.10,0.30)$, and another even narrower range in the upper limit $(0.10,0.25)$ for the with-shell configuration. The effect of the presence of the orchestra shell on this early lateral energy parameter in the audience seats although small is audible, as seen in Bradley's work on a set of American halls (BRADLEY, 1996).

Complementary to these statements, Figs. 4b and $4 \mathrm{c}$ include the results of the percentage of data in each positional interval for this parameter, in steps of $1 \mathrm{JND}$ in each interval, whereby only those results of the parameter for which there are significant values above $10 \%$ in all areas are included. These results correspond to the range from 0.10 to 0.30 for the stage without the orchestral shell and are similar to the conclusion drawn from Fig. 3b, and from 0.10 to 0.25 for the shell configuration. It is also worth noting that the black bar does not appear if the shell is present.

\subsubsection{Late lateral level $L_{J m}$}

A similar analysis was performed with the other monaural parameter associated with the subjective perception, known as the envelopment of sound for the subject, $L_{J m}$. Thus Fig. 5 a shows the experimental results obtained at the two source positions in all halls without the shell, and the averaged values of the parameter in the different positional areas. Mean values are very similar in all positional zones, and lower spatial dispersion is present at the centre of the stalls and in the vicinity of the side walls. Furthermore, it is worth noting that the range of variation of the parameter studied in all the rooms can be set from $-6 \mathrm{~dB}$ to $0 \mathrm{~dB}$ which is a narrower range of variation from the typical range specified in ISO 3382-1 for concert halls and multipurpose rooms with a volume $<25,000 \mathrm{~m}^{3}$.

For the completion of this study, and in order to normalize the distribution of data, Fig. $5 \mathrm{~b}$ presents the percentage of the amount of data, in steps of $2 \mathrm{~dB}$, relative to the total amount of data in each positional interval against these spatial intervals. It is worth noting that for the highest interval $(-2 \mathrm{~dB}$, $0 \mathrm{~dB}$ ) there is an increment of reception points from the centre of the halls to the lateral walls (black bar), except for the $x / w>1$ positions. Since the JND of this parameter remains unknown, the value of $2 \mathrm{~dB}$ 
a)

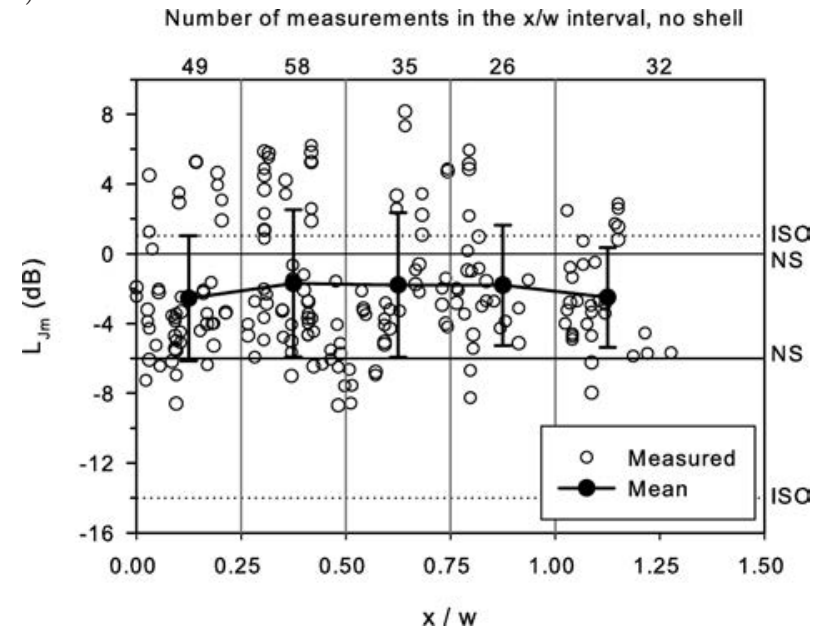

b)

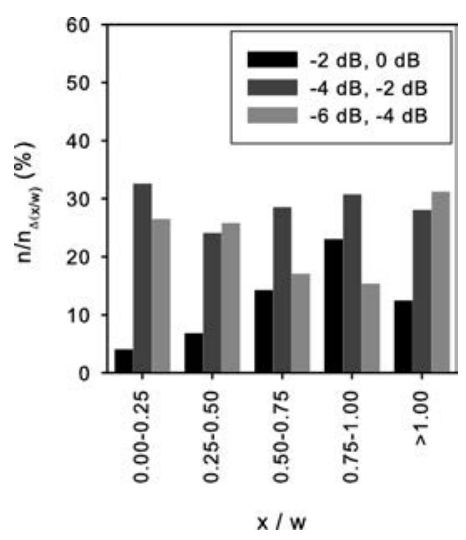

Fig. 5. a) Averaged late lateral level in the different intervals of normalized distance to the central axis of the halls: for all halls, the two source positions and without orchestra shell. The means and their standard deviation values are also shown, together with the typical range of values in this work and the typical range in ISO 3382-1; b) fraction of data for values of $L_{J m}$ in steps of $2 \mathrm{~dB}$ in the different intervals of $x / w$ relative to the total amount of data in the same interval, for all halls without the orchestra shell on the stage.

has been chosen due to the wide range of the variation: from $-8.57 \mathrm{~dB}$ to $+8.15 \mathrm{~dB}$. In this representation, the results of the values of this parameter that fail to present a significant amount of data (above 10\%) in all positional zones are ignored.

By restricting the study to the 4 rooms in which acoustic measurements were taken in the two configurations, with and without the orchestra shell on the stage, set of Figs. 6, the averaged values remain constant in all positional areas and confirm the behaviour of the parameter values in all rooms studied in Fig. 5a, although slightly higher values are encountered. Both Figs. 5a and 6a, maintain the upper value of the range of variation of the parameter in these spaces $(0 \mathrm{~dB})$ despite the significant number of points that are ignored above $0 \mathrm{~dB}$, because they are less than $10 \%$ in each $2 \mathrm{~dB}$ jump. Furthermore, these results relate mostly to receptors of MFA (this space has no orchestral shell) and are therefore not shown in Fig. 6a. In fact, the distribution of mean values is approximately $-2 \mathrm{~dB}$ when the shell is present and approximately $-4 \mathrm{~dB}$ in its absence (Fig. 6a). The gap between the two configurations tends to decrease for the areas closest to the side walls $(x / w>0.75)$. Regarding the spatial dispersion as assessed by the standard deviation, this is generally in the same order of magnitude for the two configurations of the stage, in all positional zones of the audience area.

a)

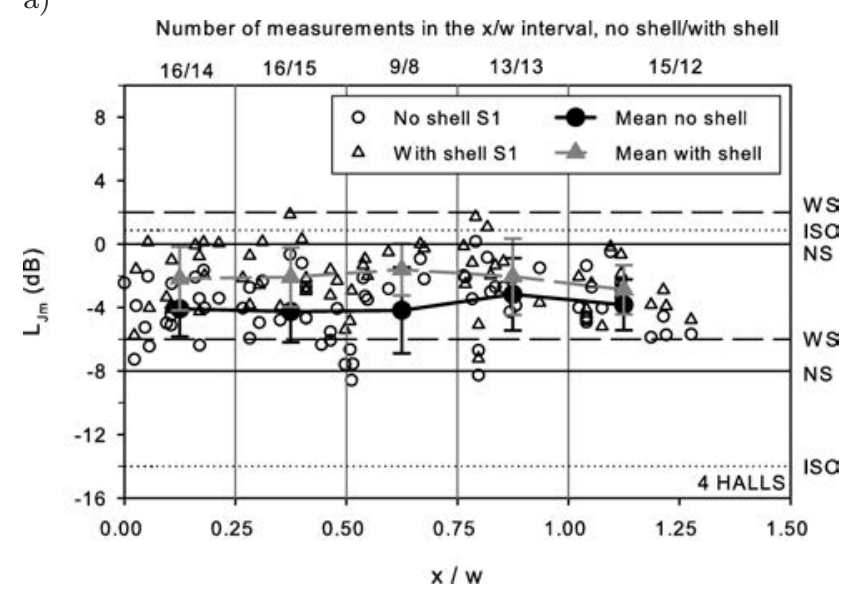

b)

c)

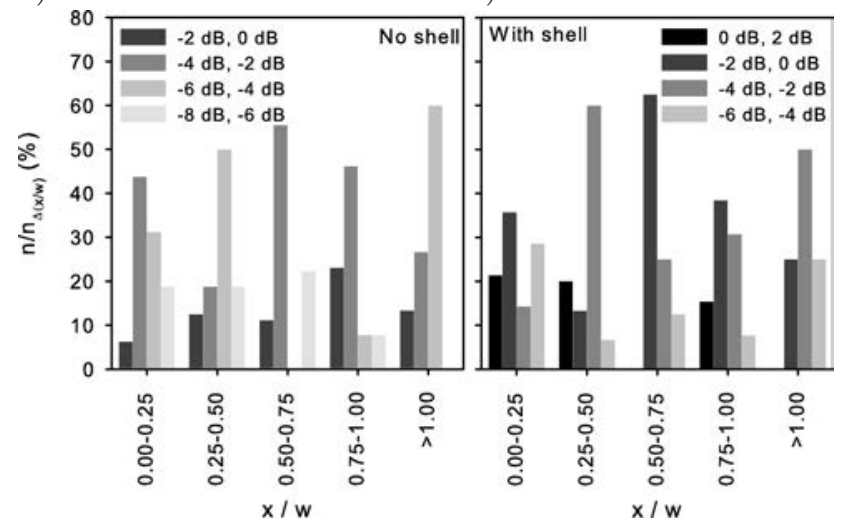

Fig. 6. a) Late lateral level results in the different intervals of normalized distance to the central axis of the halls for 4 halls, at S1 source position and for the two stage configurations. The mean values and their standard deviations for each interval are also shown, together with the typical range of values in this work and the ISO 3382-1 range; b) fraction of data for values of $L_{J m}$ in steps of $2 \mathrm{~dB}$ in the different intervals of $x / w$, relative to the total amount of data in the same interval, for 4 halls without the orchestra shell; c) idem with the orchestra shell on the stage.

As for the complementary study conducted through Figs. $6 \mathrm{~b}$ and $6 \mathrm{c}$, the dataset with values of $n / n_{\Delta x}$ above the $10 \%$ limit suggests shortening the $L_{J m}$ typical values to between $-8 \mathrm{~dB}$ and $0 \mathrm{~dB}$ for the without-shell configuration, in Fig. 5b the range is narrower $(-6 \mathrm{~dB}$, $0 \mathrm{~dB}$ ), and between $-6 \mathrm{~dB}$ and $+2 \mathrm{~dB}$ for the configuration with the shell. The shell therefore increases the 
late lateral reflections in general in all parts of the audience and especially in the central area of the rooms (stalls and central part of upper terraces), as evidenced by the distribution of Figs. $6 \mathrm{~b}$ and $6 \mathrm{c}$ : when the shell is present, the black bar corresponding to the upper interval ( $0 \mathrm{~dB}, 2 \mathrm{~dB})$ appears, and if there is no shell, then the clearest grey bar corresponding to the lower interval $(-8 \mathrm{~dB},-6 \mathrm{~dB})$ appears.

\subsubsection{Analysis of the three parameters $J_{L L F m}$, $\left(1-I A C C_{E m}\right)$, and $\left(1-I A C C_{L m}\right)$}

The behaviour of the remaining three acoustic parameters in the various positional areas is presented in Table 2. In the following, the most salient features for each parameter are outlined:

It is noted that mean values of monaural parameter $J_{L L F m}$, have a monotonically increasing behaviour (approximately linear) from centre positions of the room to areas closest to the side walls. On approaching the areas the closest to the walls of the enclosure the presence of a shell (Table 2, first row) represents a significant decrease in mean $J_{L L F m}$ (between 0.04 and 0.09 ) whose percentage is between $13 \%$ and $24 \%$. The typical range found in this work for this parameter is from 0.20 to 0.40 in the no-shell configuration, and 0.20 to 0.35 in the with-shell configuration. Data on the typical range of this acoustic parameter is not available since it is not included in ISO 3382-1 (ISO, 2009).

When this methodology of analysis is applied to binaural parameters, it is found that, for $\left(1-\mathrm{IACC}_{E m}\right)$ mean values, no significant differences between the areas or in spatial dispersions evaluated by the standard deviation are detected, both for the full sample of halls or when considering the four halls measured in the double stage configuration. A smooth maximum appears for only $x / w \in(0.50,0.75)$. Focusing on the sample of four halls with the double stage configuration, the behaviour is very similar, and therefore the presence of the shell has no significant effect on either the mean or the standard deviation of each area. Only in the $x / w \in$ $(0.25,0.50)$ zone does the presence of the shell represent an increase of 0.07 in the value of this parameter, close to 1 JND. In all cases studied, the typical range of parameter $\left(1-\mathrm{IACC}_{E m}\right)$ in these spaces is from 0.40 to 0.70 for all values, which constitutes a range of about 4 JND.

Finally, the parameter $\left(1-\mathrm{IACC}_{L m}\right)$ presents very homogeneous spatial behaviour, regardless of whether the full sample of rooms or the four halls measured by the two stage configurations (Table 2) are considered. Standard deviations (about 0.05 in all cases), which also appear in Table 2, show that no major spatial dispersions are present. The typical range of this parameter in these performance spaces stands at 0.75 to 0.90 for all situations, regardless of whether the full sample of halls or the four halls with the two stage configuration are considered. Therefore, in terms of JND recognized in ISO 3382-1, this range of variation has an amplitude of only 2 JND and the measure of the dispersion is a mere 0.5 JND.

This means that the spatial discrimination power of the parameter is very limited, both within the different areas of the same room, and between different rooms. This is consistent with the physical significance of the parameter that evaluates the similarity of the later part (for $t>80 \mathrm{~ms}$ ) of the signals received by each ear.

\subsection{Effect on the parameters of the receiver locations with reference to the two source positions}

As stated above (Subsec. 2.1), the two positions of the sound source have been in all cases on stage: S1 at

Table 2. Mean values of $J_{L L F m},\left(1-\mathrm{IACC}_{E m}\right)$, and (1-IACC $\left.\mathrm{Im}_{L m}\right)$ acoustic parameters and their standard deviations (SD) in the different positional intervals.

\begin{tabular}{|c|c|c|c|c|c|c|c|c|c|c|c|c|}
\hline & \multirow[b]{2}{*}{$\Delta x / w$} & \multicolumn{5}{|c|}{ No shell } & \multicolumn{5}{|c|}{ With shell } \\
\hline & & & $\begin{array}{l}0.00 \\
0.25\end{array}$ & $\begin{array}{l}0.25 \\
0.50\end{array}$ & $\begin{array}{l}0.50 \\
0.75\end{array}$ & $\begin{array}{l}0.75 \\
1.00\end{array}$ & $>1.00$ & $\begin{array}{l}0.00 \\
0.25\end{array}$ & $\begin{array}{l}0.25 \\
0.50\end{array}$ & $\begin{array}{l}0.50 \\
0.75\end{array}$ & $\begin{array}{l}0.75 \\
1.00\end{array}$ & $>1.00$ \\
\hline \multirow{4}{*}{$J_{L L F m}$} & \multirow{2}{*}{4 halls $^{a}(\mathrm{~S} 1)$} & Mean $^{c}$ & 0.25 & 0.30 & 0.32 & 0.34 & 0.38 & 0.25 & 0.27 & 0.28 & 0.28 & 0.29 \\
\hline & & $\mathrm{SD}^{d}$ & 0.04 & 0.06 & 0.04 & 0.06 & 0.06 & 0.04 & 0.05 & 0.04 & 0.08 & 0.05 \\
\hline & \multirow{2}{*}{$\mathrm{All}^{b}(\mathrm{~S} 1+\mathrm{S} 2)$} & Mean & 0.27 & 0.28 & 0.31 & 0.34 & 0.34 & - & - & - & - & - \\
\hline & & SD & 0.07 & 0.06 & 0.07 & 0.07 & 0.08 & - & - & - & - & - \\
\hline \multirow{4}{*}{$\left(1-\mathrm{IACC}_{E m}\right)$} & \multirow{2}{*}{4 halls (S1) } & Mean & 0.51 & 0.52 & 0.60 & 0.60 & 0.54 & 0.53 & 0.59 & 0.59 & 0.59 & 0.55 \\
\hline & & SD & 0.12 & 0.14 & 0.08 & 0.09 & 0.11 & 0.09 & 0.11 & 0.11 & 0.11 & 0.11 \\
\hline & \multirow{2}{*}{ All $(\mathrm{S} 1+\mathrm{S} 2)$} & Mean & 0.52 & 0.56 & 0.61 & 0.58 & 0.59 & - & - & - & - & - \\
\hline & & SD & 0.12 & 0.12 & 0.10 & 0.10 & 0.11 & - & - & - & - & - \\
\hline \multirow{4}{*}{$\left(1-\mathrm{IACC}_{L m}\right)$} & \multirow{2}{*}{4 halls (S1) } & Mean & 0.80 & 0.81 & 0.84 & 0.83 & 0.82 & 0.80 & 0.82 & 0.82 & 0.85 & 0.83 \\
\hline & & SD & 0.05 & 0.04 & 0.04 & 0.04 & 0.03 & 0.06 & 0.05 & 0.05 & 0.04 & 0.04 \\
\hline & \multirow{2}{*}{ All $(\mathrm{S} 1+\mathrm{S} 2)$} & Mean & 0.82 & 0.84 & 0.85 & 0.85 & 0.83 & - & - & - & - & - \\
\hline & & SD & 0.05 & 0.05 & 0.04 & 0.04 & 0.04 & - & - & - & - & - \\
\hline
\end{tabular}

${ }^{a}$ CGT, FGT, MCT and VT: Halls with both measurements, without and with shell in S1. ${ }^{b}$ All halls with mea-

surements in S1 and S2 without shell. ${ }^{c}$ Average values of each zone. ${ }^{d}$ Standard deviation of each zone. 
the axis of symmetry or centre of the room; and $\mathrm{S} 2$, a position shifted to the right as seen from the audience towards the stage (in ICT no shell, LVT no shell, and MFA no shell room A), or shifted to the left (FGT with shell, MCT with shell, MFA no shell room B, MT with shell, and VT no shell).

In order to assess the impact of the sound source position in the acoustic parameters analyzed, the absolute values of the differences of the parameters at each reception point have been studied within the 7 performance venues, in which these measures are available as specified above. The positions of the reception points have been specified according to how they view the two positions of the source on stage, both on the right (RS1-RS2), one on the right-hand side and another on the left, or vice versa (RS1-LS2, LS1-RS2), or both source positions on the left (LS1-LS2). Figure $7 \mathrm{a}$

a)

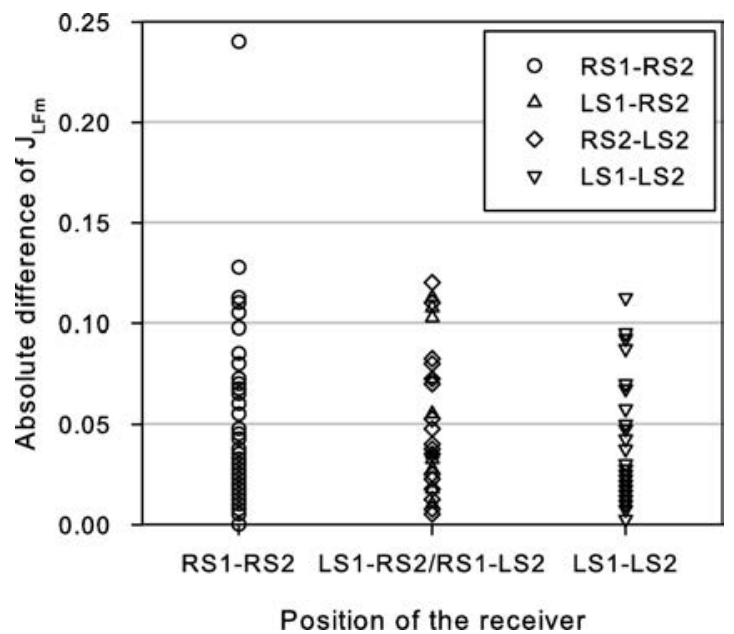

b)

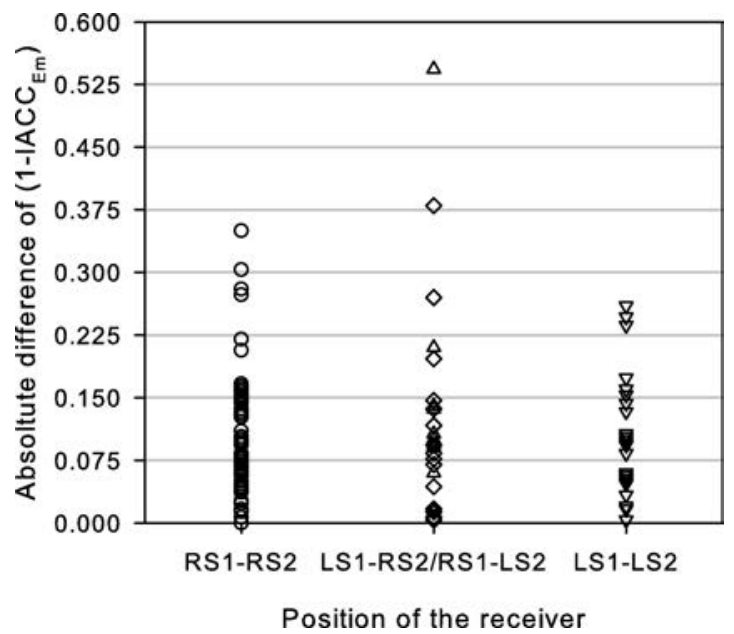

Fig. 7. Absolute differences between the values of: a) $J_{L F m}$, and b) (1-IACC $\mathrm{C}_{E m}$ ), for the two source positions at the reception points for all concert halls. The various symbols of the reception points take into account how these see the two sources: both on the right ( $\mathrm{RS} 1-\mathrm{RS} 2)$, one on the righthand side and another on the left or vice versa (RS1-LS2, LS1-RS2), or both on the left (LS1-LS2). shows the results for all rooms, and specifies the values of the $J_{L F m}$ parameter in the four distributions mentioned above and includes the positions of the receivers between the two sources as a single position, S1 on the left-hand side and $\mathrm{S} 2$ on the right-hand side or vice versa (i.e. LS1-RS2, RS1-LS2).

The dispersion of the differences is practically the same for all three spatial distributions of the reception points in all rooms, and the differences are in the range from 0 to 2 JND if the value of receiver 3 at RS1-RS2 in $\mathrm{VT}$ is omitted. For the $L_{J m}$ parameter, the dispersion of the results is higher than in the previous case, and can reach $3 \mathrm{~dB}$, by omitting two receivers: receiver 8 in $\mathrm{MCT}$, and receiver 23 in MFA (results not graphically shown).

As for the binaural parameter $\left(1-\mathrm{IACC}_{E m}\right)$, its dispersions are higher and may reach up to 4 JND with somewhat less scatter when the two sources are located on the left of the receiver (Fig. 7b). However no singularity associated with each of the settings in the position from the source has been detected in the five parameters studied related with spatial effects.

Since the observed behaviour pattern is very similar in all five acoustic parameters studied, the figures below show the results of only three parameters: $J_{L F m}$ in Fig. 8a, $L_{J m}$ in Fig. 8b, and (1-IACC ${ }_{E m}$ ) in Fig. 8 c, respectively. In all plotted graphs, the absolute values of the parameter differences for the two positions of the source scaled with steps of 1 JND are shown in ordinates (if known or proposed (ISO, 2009), in the case of $L_{J m}$ parameter in steps of $1 \mathrm{~dB}$ ), and in abscissas the 7 concert halls in acronyms in alphabetical order and by specifying the stage configuration after the acronyms (with shell "ws", no shell "ns"). In addition, the top of the graphs specify the typology of the halls, namely: horseshoe proscenium (HP), shoebox proscenium (SP), rectangular auditorium (RA), and cylindrical auditorium (CA).

In relation to Fig. 8a, results indicate that except for a position in VT, (receptor 3 on the ground floor at a side terrace below the terrace of the first floor), almost all differences in this parameter are in the range of 1 to 2 JND with a count of more positions with absolute differences lower than 1 JND; the corresponding points that present a difference between 1 and 2 JND are at the seats under balconies. Although they have been considered, no significant differences were found exclusively associated with the change of sourcereceiver distance and no significant differences were observed related to the presence of the orchestra shell on stage.

As for the influence of the various typologies, a greater uniformity in the horseshoe proscenium typology can be observed, at least clearly in two cases, LVT and MCT, the differences are found in values $<1$ JND, and greater dispersion is discovered in the case of shoebox and auditorium typologies. 
a)

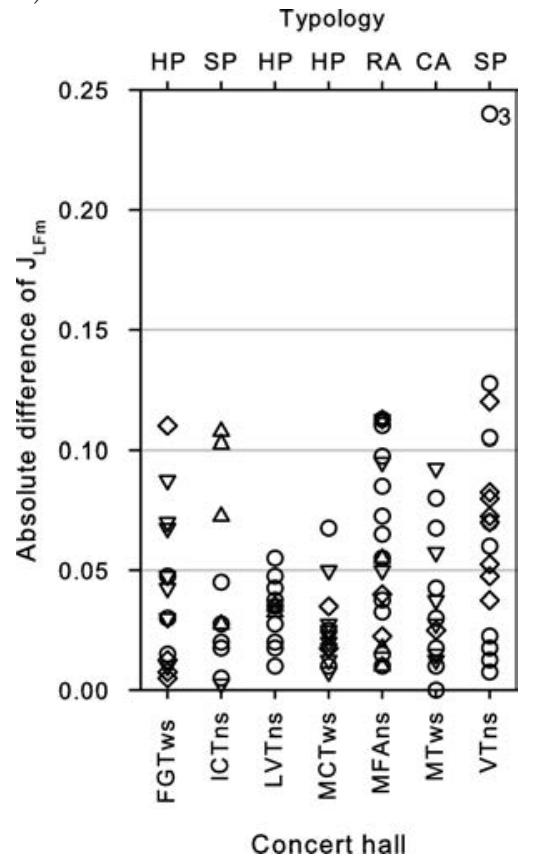

b)

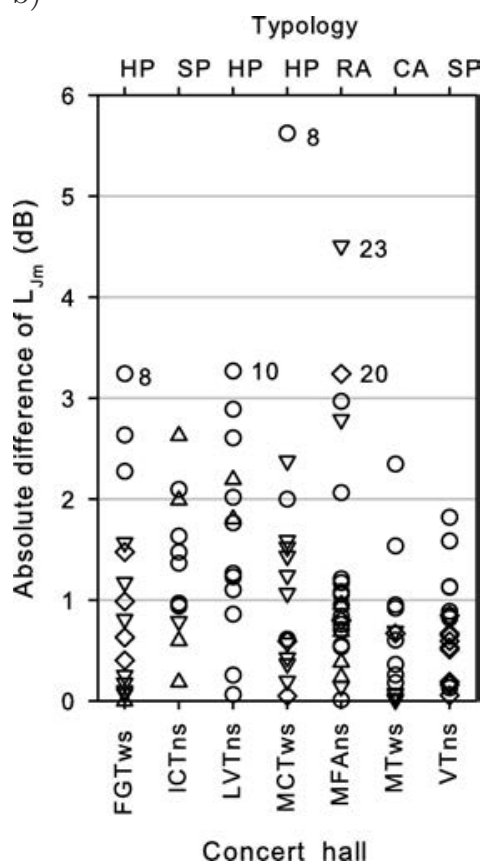

c)

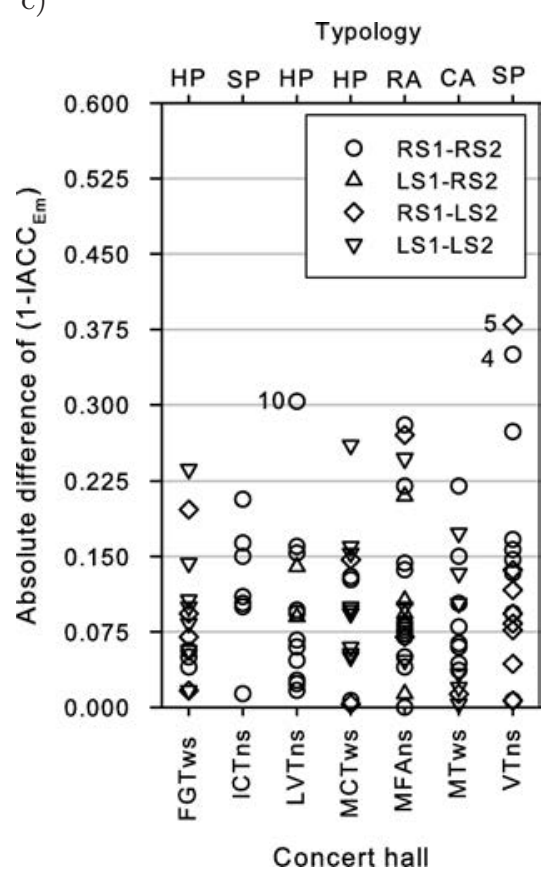

Fig. 8. Absolute differences between the values of: a) $J_{L F m}$, b) $L_{J m}$, and c) (1-IACC $E m$ ), for the two source positions in each concert hall. The various symbols of the reception points take into account how these see the two sources: both on the right (RS1-RS2), one on the right-hand side and another on the left or vice versa (RS1-LS2, LS1-RS2), or both on the left (LS1-LS2).

With regards to the monaural parameter of final lateral energy $L_{J m}$, in these performance areas, a higher dispersion of the differences of the parameter can be observed of up to $3 \mathrm{~dB}$, Fig. $8 \mathrm{~b}$, (the positions that differ exceptionally more than $3 \mathrm{~dB}$ are: in MCT, at receiver 8 in the stalls below the roof of the boxes on the first floor; in MFA, at receiver 23 which is in the back of room B; less deviation in receiver 8 in the stalls in FGT, under the roof of the boxes on the first floor; at receiver 10 in $\mathrm{LVT}$ in the left box on the first floor; and at receiver 20 of MFA in room B). Again, predictable behaviour cannot be attributed to the orchestra shell on stage, to the source-receiver distance, and there is a large concentration of values in most of the hall areas with differences of less than $2 \mathrm{~dB}$. Regarding the various typologies involved, behaviour of a slightly more homogeneous nature (within $1 \mathrm{~dB}$ ) can be observed in auditorium typology (MFA room A, and MT).

Figure 8c displays the equivalent study for the parameter (1-IACC $\mathrm{Im}_{\mathrm{m}}$ ) which shows a data distribution similar to that of Fig. 8a, and that, except in exceptional reception points, (LVT receiver 10 located on the first floor on the left, and VT receivers 4 and 5 on the ground floor in the stalls), the parameter maintains the differences in values from the two source positions within 2 JND for almost all halls.

Similar comments can be made with respect to the other two parameters that quantify the late lateral sound energy, $J_{L L F m}$ and $\left(1-\mathrm{IACC}_{L m}\right)$, which have not been presented in graphical form. It should also be mentioned here that a study has been carried out on the differences in the parameters due to the effect of change in the sound source position as a function of source-receiver distance and on the positions of the listener with respect to the side walls of the enclosure, whereby no predictable behaviour was detected in the performance halls studied separately, nor as a whole.

Finally, in addition to the graphical information provided in previous figures, Table 3 shows the percentage of data in all halls studied, in which the absolute differences are between 0 and 1 JND, between 1 and 2 JND, and more than 2 JND, respectively, for all parameters studied.

Table 3. Percentage of reception points $(q)$ included in the various JND intervals, for the absolute differences of the parameter values at the two source positions when all halls are considered together.

\begin{tabular}{|l|c|c|c|}
\hline Parameter & $q<1$ JND & 1 JND $<q<2$ JND & $q>2$ JND \\
\hline$J_{L F m}$ & 66.4 & 23.6 & 10 \\
\hline$J_{L L F m}$ & 58.2 & 33.6 & 8.2 \\
\hline$L_{J m}$ & 58.2 & 24.5 & 17.3 \\
\hline (1-IACC $\left._{E m}\right)$ & 37.3 & 41.8 & 20.9 \\
\hline (1-IACC $\left._{L m}\right)$ & 88.2 & 11.8 & 0 \\
\hline
\end{tabular}

From Table 3 it can be highlighted that for the energy parameters which account for the early lateral acoustic energy, the vast majority of the differences are $<1$ JND or between 1 and 2 JND when all the enclosures are analyzed together. For the parameters of late 
lateral acoustic energy, the differences are even more uniform, and most of the points lie in differences $<1$ JND. Everything indicates therefore, that in the early lateral energy there are audible variations from one point to another captured by the change in the position of the sound source, whilst in the final energy there is no detectable change in these performance areas.

\subsection{Other relationships between measures}

Although monaural lateral fraction measures and inter-aural cross-correlation measures are conceptually dissimilar and it is not obvious that they are related to each other, these two measurements in different halls (Gade, 1989; Bradley, 1994; OKano et al., 1998) have shown that hall average values are significantly correlated. In the following subsections, the relationship between these two kinds of measures are first studied while considering the individual seating positions in all halls together and the hall average values, then in an effort to associate these measures to architectural variables, the hall average values are compared with various geometrical and acoustic parameters by means of regression analysis.

\subsubsection{Comparison between monaural and binaural parameters}

This subsection compares the results obtained in the lateral monaural and binaural spectrally averaged acoustic parameters for the same early and late time intervals, respectively. The study is carried out by first considering all available data together for all the measurement positions in all rooms, including the results of the two positions of the sound source which takes place in 7 rooms, and also the results obtained with the two configurations on the stage: with and without the orchestral shell (4 rooms), thereby creating a total of 321 pairs of results. Analyses with hall-average values of the parameter are then performed.

The values of $\left(1-\mathrm{IACC}_{E m}\right)$ as a function of the $J_{L F m}$ parameter for all pairs of measurements appear in Fig. 9a, which shows a certain scattering of the results and the line of the logarithmic fit. The linear fit of the data of these two parameters is very weak with a correlation coefficient $R^{2}=0.2690$. Of a similar order are the fits obtained between these two variables with a logarithmic or hyperbolic type whose results are laid out in Eqs. (5) and (6) respectively:

$$
\begin{gathered}
\left(1-\mathrm{IACC}_{E m}\right)=0.177 \ln \left(J_{L F m}\right)+0.876, \\
R^{2}=0.3184, \quad P<0.0001, \\
\left(1-\mathrm{IACC}_{E m}\right)=\frac{3.223 J_{L F m}}{0.389+J_{L F m}} \\
\quad+\frac{0.034 J_{L F m}}{-0.041+J_{L F m}}-2.663 J_{L F m}, \\
R^{2}=0.3439, \quad P<0.0001 .
\end{gathered}
$$

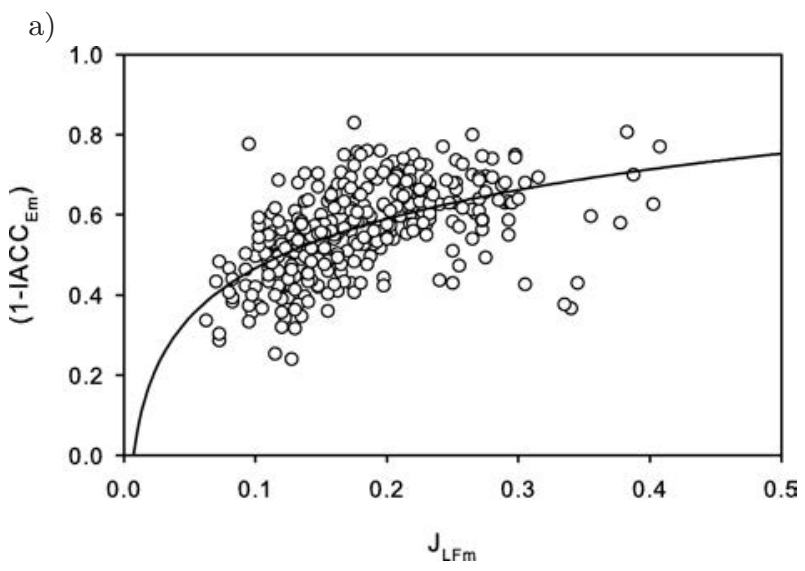

b)

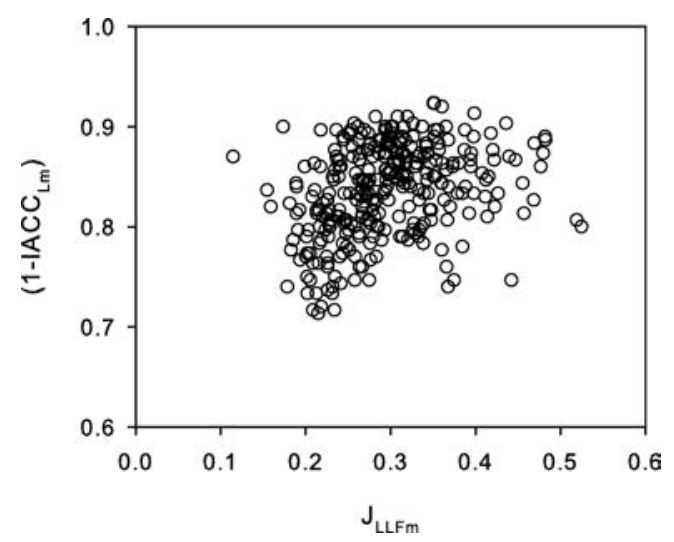

c)

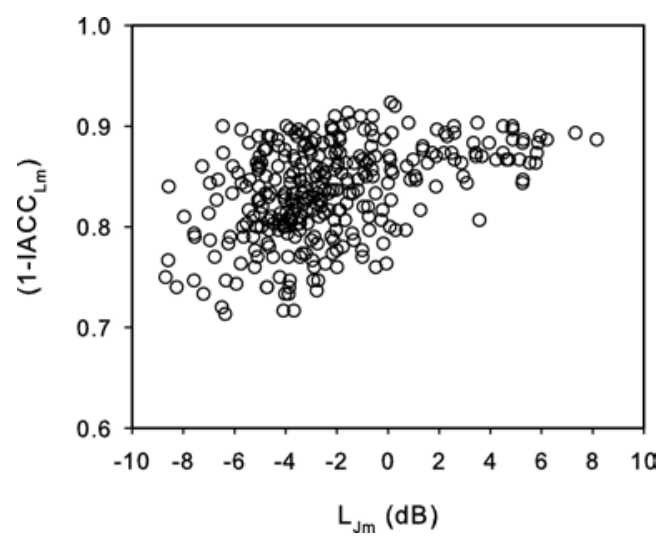

Fig. 9. a) (1-IACC $C_{E m}$ ) versus $J_{L F m}$ and the line of the logarithmic fit; b) (1-IACC $\left.\mathrm{Im}_{L m}\right)$ versus $J_{L L F m}$; c) $\left(1-\mathrm{IACC}_{L m}\right)$ versus $L_{J m}$, where all values are given for all individual positions in the halls with the two source positions and two configurations of the stages.

A similar lack of correlation is found by Bradley in his work, with the whole set of data considered in the analysis (BRADLEY, 1994).

Relationships fail to improve substantially if the study is performed while considering the measurement positions in each hall. For the $\left(1-\mathrm{IACC}_{E m}\right)$ parameter against $J_{L F m}$ hall by hall, the strongest linear regression found is that for MT with a coefficient of determination $R^{2}=0.4985$, (close to this value are those 
of CGT, ICT, and MCT), while the weakest is that of MFA with a coefficient of determination $R^{2}=0.1386$, (close to this value are those of FGT, ICT, LVT, and VT), where the former auditorium is cylindricalshaped, and the latter is rectangular-shaped.

The relationship between the entire set of data (321 values) for all halls in the two configurations of the stage and at the two positions of the source of the late binaural parameter $\left(1-\mathrm{IACC}_{L m}\right)$ as a function of the late monaural $J_{L L F m}$ parameter is also studied, and is shown in Fig. 9b, while that for $\left(1-\mathrm{IACC}_{L m}\right)$ against the late lateral level $L_{J m}$ parameter is displayed in
Fig. 9c. The corresponding linear adjustments present very low values of the coefficients of the correlation, $R^{2}=0.0966$, and $R^{2}=0.1919$, respectively, which implies that they are uncorrelated.

The following regression analysis is performed by considering only the five spatially averaged parameter values, where the data used in the figures for each room appears in Table 4 . The results for $\left(1-\mathrm{IACC}_{E m}\right)$ plotted against $J_{L F m}$ are displayed in Fig. $10 \mathrm{a}$, whereby the graph includes two spatially averaged values in the two configurations of the stages (with and without the orchestra shell), together with the results of the 15 rooms

Table 4. Spatially averaged values for all positions of the microphones, range (maximum valueminimum value) and standard deviation of the acoustic parameters for each performance space, in the two configurations of the stage.

\begin{tabular}{|c|c|c|c|c|c|c|c|}
\hline Hall & Shell & & $J_{L F m}$ & $\left(1-\mathrm{IACC}_{E m}\right)$ & $J_{L L F m}$ & $\left(1-\mathrm{IACC}_{L m}\right)$ & $L_{J m}(\mathrm{~dB})$ \\
\hline \multirow{6}{*}{ CGT } & \multirow{3}{*}{$\mathrm{NO}$} & Range & 0.280 & 0.463 & 0.268 & 0.117 & 6.190 \\
\hline & & Average & 0.198 & 0.546 & 0.323 & 0.805 & -4.132 \\
\hline & & St. Dev. & 0.074 & 0.132 & 0.076 & 0.031 & 1.530 \\
\hline & \multirow{3}{*}{ YES } & Range & 0.170 & 0.393 & 0.193 & 0.153 & 4.093 \\
\hline & & Average & 0.139 & 0.573 & 0.227 & 0.809 & -2.917 \\
\hline & & St. Dev. & 0.050 & 0.113 & 0.050 & 0.046 & 1.211 \\
\hline \multirow{6}{*}{ FGT } & \multirow{3}{*}{ NO } & Range & 0.258 & 0.333 & 0.178 & 0.160 & 5.487 \\
\hline & & Average & 0.232 & 0.585 & 0.303 & 0.805 & -5.049 \\
\hline & & St. Dev. & 0.080 & 0.089 & 0.058 & 0.052 & 1.836 \\
\hline & \multirow{3}{*}{ YES } & Range & 0.265 & 0.373 & 0.196 & 0.143 & 5.867 \\
\hline & & Average & 0.180 & 0.550 & 0.262 & 0.831 & -3.214 \\
\hline & & St. Dev. & 0.069 & 0.108 & 0.046 & 0.045 & 1.750 \\
\hline \multirow{3}{*}{ HGT } & \multirow{3}{*}{ NO } & Range & 0.243 & 0.297 & 0.287 & 0.107 & 6.899 \\
\hline & & Average & 0.247 & 0.647 & 0.343 & 0.852 & -1.765 \\
\hline & & St. Dev. & 0.073 & 0.074 & 0.073 & 0.028 & 2.156 \\
\hline \multirow{3}{*}{ ICT } & \multirow{3}{*}{ NO } & Range & 0.153 & 0.543 & 0.238 & 0.140 & 6.606 \\
\hline & & Average & 0.137 & 0.558 & 0.243 & 0.822 & -5.196 \\
\hline & & St. Dev. & 0.032 & 0.106 & 0.060 & 0.040 & 1.525 \\
\hline \multirow{3}{*}{ LVT } & \multirow{3}{*}{ NO } & Range & 0.195 & 0.343 & 0.185 & 0.147 & 7.908 \\
\hline & & Average & 0.180 & 0.564 & 0.241 & 0.800 & -4.286 \\
\hline & & St. Dev. & 0.047 & 0.102 & 0.040 & 0.039 & 1.731 \\
\hline \multirow{6}{*}{ MCT } & \multirow{3}{*}{$\mathrm{NO}$} & Range & 0.178 & 0.407 & 0.326 & 0.123 & 8.086 \\
\hline & & Average & 0.164 & 0.486 & 0.336 & 0.816 & -4.516 \\
\hline & & St. Dev. & 0.058 & 0.115 & 0.075 & 0.036 & 2.258 \\
\hline & \multirow{3}{*}{ YES } & Range & 0.225 & 0.453 & 0.314 & 0.190 & 11.152 \\
\hline & & Average & 0.182 & 0.541 & 0.309 & 0.813 & -1.969 \\
\hline & & St. Dev. & 0.058 & 0.113 & 0.066 & 0.046 & 2.213 \\
\hline \multirow{3}{*}{$\begin{array}{l}\mathrm{MFA} \\
\mathrm{A}+\mathrm{B}\end{array}$} & \multirow{3}{*}{ NO } & Range & 0.208 & 0.377 & 0.254 & 0.087 & 7.358 \\
\hline & & Average & 0.188 & 0.614 & 0.321 & 0.875 & 3.791 \\
\hline & & St. Dev. & 0.053 & 0.098 & 0.061 & 0.019 & 1.807 \\
\hline \multirow{3}{*}{ MT } & \multirow{3}{*}{ YES } & Range & 0.283 & 0.420 & 0.219 & 0.090 & 4.471 \\
\hline & & Average & 0.180 & 0.526 & 0.310 & 0.874 & -3.278 \\
\hline & & St. Dev. & 0.067 & 0.121 & 0.046 & 0.024 & 1.042 \\
\hline \multirow{6}{*}{ VT } & \multirow{3}{*}{ NO } & Range & 0.340 & 0.510 & 0.278 & 0.180 & 5.667 \\
\hline & & Average & 0.163 & 0.512 & 0.317 & 0.854 & -2.255 \\
\hline & & St. Dev. & 0.064 & 0.111 & 0.076 & 0.043 & 1.238 \\
\hline & \multirow{3}{*}{ YES } & Range & 0.243 & 0.320 & 0.212 & 0.133 & 4.011 \\
\hline & & Average & 0.180 & 0.604 & 0.290 & 0.840 & -0.177 \\
\hline & & St. Dev. & 0.056 & 0.079 & 0.055 & 0.039 & 1.080 \\
\hline
\end{tabular}


a)

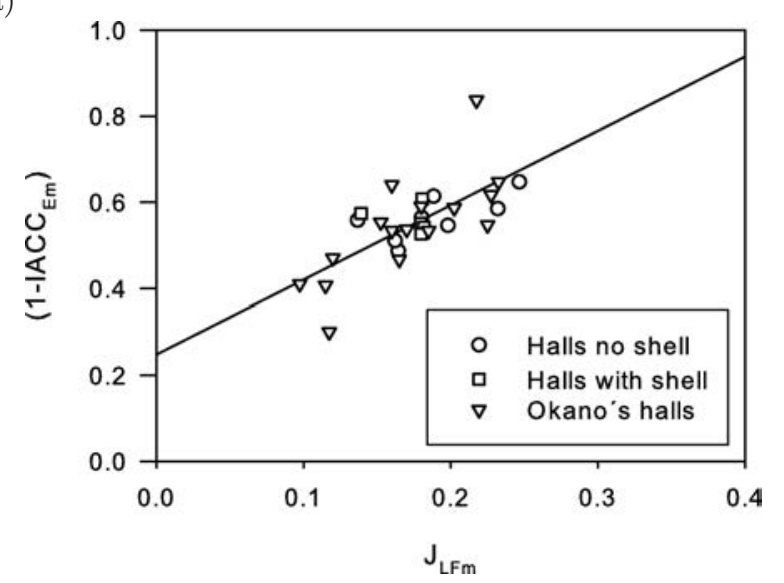

b)

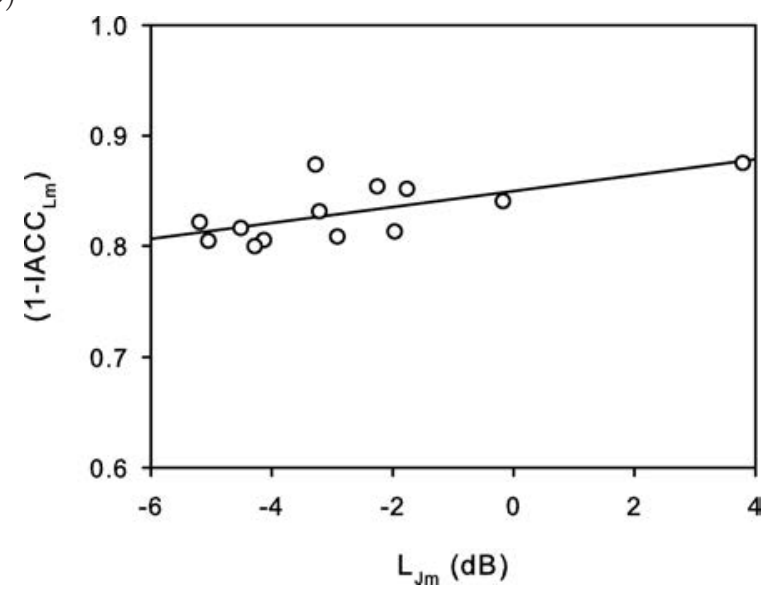

Fig. 10. a) Hall-average values of (1-IACC $E m$ ) versus $J_{L F m}$ values in this work, and those in the study by Okano and their linear regression; b) Hall-average values of (1$\mathrm{IACC}_{L m}$ ) versus $L_{J m}$ values in this work in the two configurations of the stages, and their linear regression.

provided in Okano's work (OKANO et al., 1998) for comparison purposes, whose linear fit for all this data corresponds to the mathematical equation of Eq. (7).

$$
\begin{gathered}
\left(1-\mathrm{IACC}_{E m}\right)=1.727 J_{L F m}+0.242, \\
R^{2}=0.4860, \quad P<0.0001 .
\end{gathered}
$$

The correlation is stronger here than that when the whole set of data in all halls studied is considered together, and becomes even stronger than that correlation when only the hall average data of this set of halls under investigation is considered, as displayed in Eq. (8):

$$
\begin{gathered}
\left(1-\mathrm{IACC}_{E m}\right)=0.745 J_{L F m}+0.426, \\
R^{2}=0.2836, \quad P=0.0610 .
\end{gathered}
$$

As in the former case where the number of halls is representative, it can be inferred that there is an acceptable correlation between the spatially averaged values of the two parameters.
Due to the absence of results in Okano's work in relation to monaural and binaural parameters for the late lateral energy, a similar comparison to that above is not possible.

By reducing the relationships to only those that are possible with this work, then the following equation can be given:

$$
\begin{gathered}
\left(1-\mathrm{IACC}_{L m}\right)=0.007 L_{J m}+0.850, \\
R^{2}=0.4388, \quad P=0.0136
\end{gathered}
$$

whose results appear in Fig. 10b. The regression of (1IACC $_{L m}$ ) with $J_{L L F m}$ parameter is very weak $R^{2}=$ 0.0517. The observation that dispersion is greater in the relationship between binaural and monaural parameters when studying all positions of the microphones and all rooms than when the study is restricted to one room or hall-averaged values is also found by BRADLEY (1994) in his report and in the comparison between the values of the two types of measures obtained in 14 concert halls, where analyses were performed in terms of both hall-average values as well as individual positions.

It is worth noting that the spatially averaged values of the parameters displayed in Table 4 enable the ratification of those comments put forward when the spatial distribution of the parameters in Subsec. 3.1 were studied, and it is also pertinent to highlight the high and positive value of $L_{J m}$ parameter in MFA, as stated in Subsec. 3.1.2.

\subsubsection{Relationship with architectural and acoustic parameters}

Finally with the aim of associating monaural and binaural lateral energy fraction measures to architectural variables, the hall-average values of the five acoustic parameters $J_{L F m}, J_{L L F m}, L_{J m},\left(1-\mathrm{IACC}_{E m}\right)$, and $\left(1-\mathrm{IACC}_{L m}\right.$ ) (displayed in Table 4) are studied as a function of the following six geometrical dimensions of the halls: mean-width, $W$; mean-height/meanwidth ratio, $H / W$; mean-height/mean-depth ratio, $H / D ;$ mean-depth/mean-width ratio, $D / W$; total volume/number of seats ratio, $V / N$; audience surface/number of seats ratio, $S_{A} / N$. These geometric parameters have been calculated in the halls according to those specified in Subsec. 2.2. Relationships of these acoustic parameters against the total absorption of the halls $A$, and reverberation time $T$, are also studied (reverberation times averaged in the 500 and $1000 \mathrm{~Hz}$ octave bands in the halls and averaged total absorption, are shown in the last rows of Table 1 ).

The most significant dependencies are represented by the highest value of the coefficient of the determination, $R^{2}$. The significant $P$ values have also been indicated and it can usually be concluded that the independent variable can be used to predict the dependent variable when $P<0.05$. 
In all cases, the linear fits studied show very weak correlations. Taking into account the aforementioned assumptions, the only reliable correlations are those of (1-IACC $\mathrm{Em}_{E m}$ ) with $A$ (with negative slope), (1$\mathrm{IACC}_{L m}$ ) with $T$, whereby the parameter increases when reverberation time increases, and that of $L_{J m}$ with $V / N$ which also has a positive slope Eqs. (10)(12). The values and linear regressions corresponding to the binaural parameters are plotted in Figs. 11a and $b$, respectively.

$$
\begin{gathered}
L_{J m}=-0.763(V / N)+5.159, \\
R^{2}=0.4861, \quad P=0.0081, \\
\left(1-\mathrm{IACC}_{E m}\right)=-0.0001 A+0.668, \\
R^{2}=0.5538, \quad P=0.0035, \\
\left(1-\mathrm{IACC}_{L m}\right)=0.044 T+0.759, \\
R^{2}=0.5828, \quad P=0.0024 .
\end{gathered}
$$

In the same way as the simple image model indicates in concert halls and opera houses, the mean hall early lateral energy fractions are influenced by the hall width. Other pieces of work have found this correlation, for instance GADE (1989) concludes that $J_{L F m}$ has no meaningful connection to diffuse field theory

a)

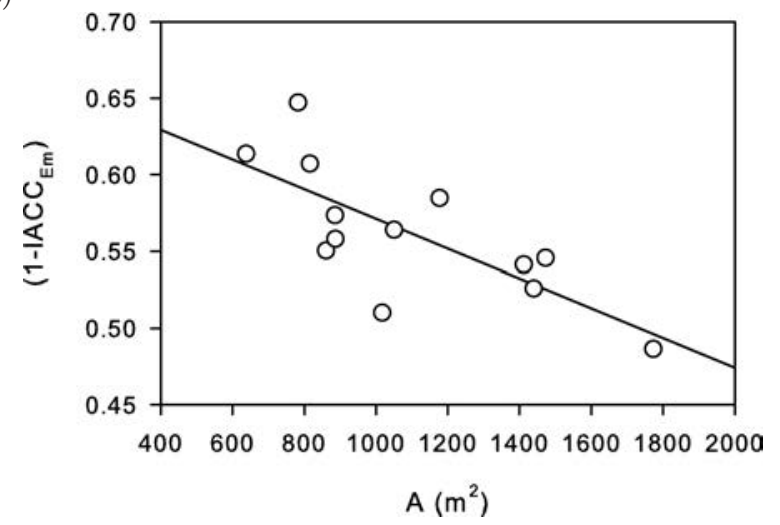

b)

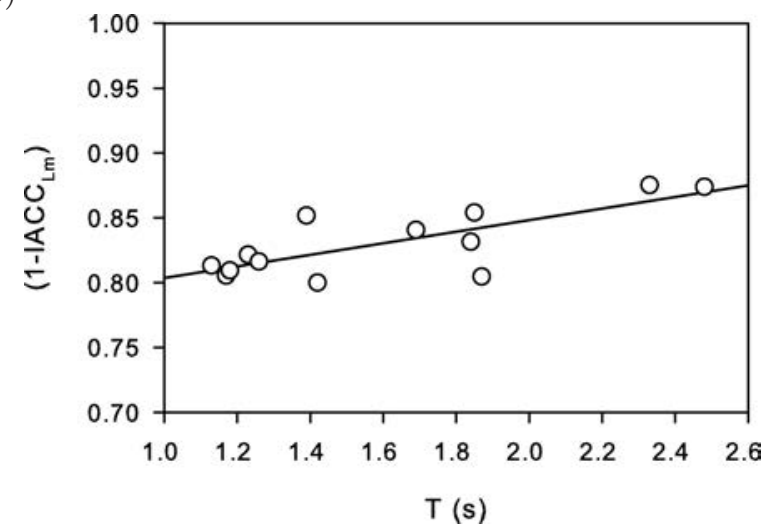

Fig. 11. a) Hall-average values of (1-IACC $\mathrm{Im}_{\mathrm{m}}$ ) versus $A$; b) $\left(1-\mathrm{IACC}_{L m}\right)$ values versus $T$, in the two configurations of the stages and their linear fits. but shows a highly significant relationship with hall width. Based on the data from all 32 halls, the correlation is $R^{2}=0.43$ and negative. However, if the analysis is restricted to 16 rectangular halls, it increases to $R^{2}=0.67$. In addition, the ratio $2 \mathrm{H} / \mathrm{W}$ which determines the relative arrival time of early lateral and vertical reflections, as WEST (1966) suggested for concert halls, seems to be a geometrical measure in connection with early lateral fraction measures. In the halls studied in this work, the two geometrical magnitudes $W$, and $2 H / W$ present a very poor relationship with the monaural fraction $J_{L F m}$ and with the binaural measure $\left(1-\mathrm{IACC}_{E m}\right)$. Perhaps the low correlation in this work is due to the fact that orchestra shells provoke audible variations in the acoustic parameters, while the associated geometrical quantities remain unchanged.

To sum up, under the large volume of data analyzed in this work and the many variables included it would be desirable to follow Bradley's very recent suggestions (BRADLEY, 2011) in connection with carrying out experimental work of a more focused nature.

\subsection{Summary and discussion}

In this section, a synopsis of the study is undertaken and the results are presented of the objective acoustic parameters, (spectrally averaged in accordance with the ISO 3382-1 standard (ISO, 2009)) that qualify the spatial impression in 9 performance halls in southern Spain (Andalusia) in the various approaches.

The dependence of monaural and binaural parameters on source-receiver distance shows no predictable behaviour and experimental results have been compared with the theoretical calculations of Barron's revised theory, which needs only the mean reverberation time and total hall volume for each hall (Subsec. 3.1, (BARron, LEE, 1988)).

The study of spatial distribution of acoustic parameters in the rooms was jointly carried out by scaling the results at intervals of $1 \mathrm{JND}\left(0.05\right.$ for $J_{L F m}$ and $J_{L L F m}, 0.075$ for $\left(1-\mathrm{IACC}_{m}\right)$ measures, and $2 \mathrm{~dB}$ for $L_{J m}$, whose JND is not known) depending on the relative positions of the points of reception to the central axis of each room (for left and right-hand sides), which were normalized relative to half their respective mean width, (Subsec. 3.1). The orchestra shell commonly produces a small but perceptible effect on these parameters measured in the audience area, since for $J_{L F m}$, Fig. 4 a, the change may reach a value of 1 JND, especially in the areas closest to the side walls. In addition, the range of variation of $J_{L F m}$ in the set of values for all rooms is $(0.10,0.30)$ in the configuration without shell (Figs. 3a and 4a), and (0.10, 0.25) with the orchestral shell, Fig. 4a, which suggests that the shell favours a redistribution of the acoustic energy in the audience area in these performance spaces. Furthermore, the average values of $J_{L F m}$ in all positional 
intervals are lower when the shell is present on stage than when it is absent. For the late lateral level $L_{J m}$, however, the shell seems to favour an increase of the parameter, and in both configurations of the stage the range of variation is also much narrower than the typical range stated in ISO 3382-1 (ISO, 2009), (-8, 0) $\mathrm{dB}$ for the no-shell configuration, and $(-6,2) \mathrm{dB}$ for the with shell, see set of Figs. 6 .

As for the binaural parameters, (Table 2), both the early lateral energy as well as the late energy exhibit similar spatial dispersion and are lower than the monaural parameters at the various positional intervals. For (1-IACC $\left.\mathrm{C}_{E m}\right)$, the typical range in these spaces is $(0.40,0.70)$ for the two configurations of the stage. Parameter (1-IACC $\mathrm{C}_{L m}$ ) exhibits the same behaviour in its mean values in each positional zone with a slight peak in the area between the central axis and side walls of the room (stalls zone). The standard deviations show that the spatial dispersions are not wide, and are slightly higher, generally, in the configuration without shell. The typical range of this parameter in these areas is $(0.75,0.90)$ regardless of whether there is an orchestra shell on stage.

The effect on lateral energy parameters measured in the audience zone due to the change of source position on stage has been also studied in terms of the absolute value of the differences in their values, scaled at intervals of 1 JND at each reception point of each room. No predictable behaviour of these differences in the parameters associated with the variation of sourcereceiver distance, nor of the different laterality of the source sound position has been detected. In a statistical survey of all reception points, classified according to how they see the source in all rooms together, most of the seats have variations that are in the range 1-2 JND for the early lateral energy parameters, whilst for the late lateral energy, most points lie within differences $<1$ JND (Figs. 7 and Table 3).

Considering the behaviour of these differences for each room, $J_{L F m}$ presents very homogeneous values in MCT and LVT halls, as shown in Fig. 8a, which both have horseshoe typology. Generally for the late lateral level, $L_{J m}$, Fig. $8 \mathrm{~b}$, a greater change is found in the values of these differences from place to place within all the halls studied.

The results of the comparison between values of the two types of measures of lateral energy (monaural and binaural for the same temporal interval) obtained in the 9 halls in all the individual positions show that the correlations are very weak and that the relationships are not statistically significant, as shown in the set of Figs. 9. However, relationships improve when the data on each hall is considered exclusively, especially in certain halls, and when all hall-average data is studied for a comparison between $J_{L F m}$ and $\left(1-\mathrm{IACC}_{E m}\right)$. In the latter case, the inclusion in the study of the results of a set of 15 halls from Okano's work (OKANo et al., 1998) further improves the correlation found (Fig. 10a). For the late lateral energy parameters, no similar data is available in the literature. However, by taking into account the values of the 9 halls studied in this work for the two configurations of the stage, the relationship between $\left(1-\mathrm{IACC}_{L m}\right)$ and $L_{J m}$ parameters becomes similar to that obtained previously for the early lateral energy parameters as shown in Fig. 10b.

Finally, the study in Subsec. 3.3.2 of the dependencies of these hall-average parameters with eight acoustic and geometrical parameters, (namely, mean width $W$, mean height-to-width ratio $H / W$, mean height-todepth ratio $H / D$, mean depth-to-width ratio $D / W$, total-volume-to-number-of-seats ratio $V / N$, audiencesurface-to-number-of-seats ratio $S_{A} / N$, reverberation time $T$, and absorption $A$ ), enables the conclusion that the statistically significant relationships are the following linear regressions between the variables: (1-IACC $\mathrm{Em}_{\mathrm{m}}$ ) with $A$, Fig. 11a, with negative slope; (1-IACC $\mathrm{Im}_{L m}$ ) with $T$, Fig. 11b, with positive slope; and that of $L_{J m}$ with $V / N$, also with negative slope. It can be observed that, in all cases, the independent variable is related to the reverberation characteristic of the room (it must be taken into account that the major absorbent surface in these spaces is the audience zone, which is closely related to the $V / N$ ratio). In this analysis, no other geometrical or acoustic variables have shown their potential influence on the values of the parameters related to spatial impression.

\section{Conclusions}

Of the various aspects studied in this work on the monaural directional and binaural parameters (spectrally averaged in accordance with the ISO 3382-1 standard) to evaluate the spatial effects of the sound fields in 9 performance spaces in Andalusia (southern Spain), it is first worth emphasising that the dependence of the parameters on source-receiver distance in each hall has revealed that lateral acoustic energy is not distributed according to the theoretical predictions of the diffuse revised theory by Barron. As a result, a common methodology has been used for all areas and parameters under study. In this methodology the position of the receiving points are expressed in relation to their distance from the symmetry axis of the room (left- and right-hand sides) normalized with respect to half the average width of the room, and the acoustic parameters are scaled at intervals of their respective JND.

The statistical treatment is the same for the parameters, data from all rooms with source in S1 and $\mathrm{S} 2$ without shell, and then the 4 rooms in which they are measured with the two configurations on the stage. The maintenance of conclusions when treating a wider statistical ensemble with the second case (smaller) gives validity to the results and conclusions when shells 
are on the stages. Statistical results show that the spatial distribution of early lateral energy fractions provides higher values for positions closer to the side walls (mean values for $x / w>1$ exceed those of the central area over 1 JND), whereas those parameters associated with late lateral energy and binaural parameters present a more uniform statistical distribution in the positional zones.

The applied methodology has allowed, for each parameter studied, the systematic establishment of their characteristic ranges for the distribution of their values for the two shell configurations on the stage. These ranges are generally smaller than those suggested in ISO 3382-1.

Statistical results have shown that the orchestral shell promotes a redistribution of acoustic energy into the audience area and produces a noticeable decrease of the early lateral energy fraction: this decrease is greater for positions close to the side walls. However, for the late lateral level the presence of the shell on stage leads to an increase in its values and a similarity in magnitude in all positional intervals. This suggests, at least initially, that shells focus sound by decreasing the initial lateral reflections, especially in the areas under balconies. This is reflected in the values of the limits of the ranges mentioned in the previous paragraph.

The change in the two positions of the sound source on stage also influences these parameters; its influence is greater on the early lateral energy parameters, and the differences found due to the change are more homogeneous for the horseshoe typology. For the late lateral energy parameters, there is a lower incidence of change in position of the sound source and results present more uniformity in auditorium typologies. The analysis has not shown that the relative position of the receiver in front of the source (left/right) has a significant effect in any of the parameters analyzed. The change in position of the source implies that, for all the parameters analysed, more than $80 \%$ of receivers of the entire enclosures experience variations lower than 2 JND. For the $\left(1-\mathrm{IACC}_{L m}\right)$ parameter, this percentage reaches $100 \%$ of receivers.

Monaural and binaural parameters describe very different physical characteristics of the sound field, and thus correlations are very weak when studying pairs of results at each position of signal reception. Exclusively when each hall is described by a single value (the spatial average) an acceptable relationship between the parameters is found both for the early and late timeinterval parameters.

Finally, in order to draw conclusions in relation to design variables, monaural and binaural parameters have been compared with the mean values of geometrical and acoustical variables of the performance spaces. Regressions show that neither the mean width, nor the mean-height/mean-width ratio is significant and that in all cases, parameters related to reverberation are the key (absorption, reverberation time, and $V / N$ ratio).

\section{Acknowledgment}

The authors wish to express their gratitude to the staff and management of each hall for their cooperation in allowing the measurements to be carried out. This work has been sponsored by FEDER funds and the Spanish Ministry of Science and Technology (MCYT) within the projects with references BIA2003-09306CO4-02, and BIA2010-20523.

\section{References}

1. Abdou A., Guy R.W. (1996), Spatial information of sound fields for room-acoustics evaluation and diagnosis, Journal of the Acoustical Society of America, 100, 3215-3226.

2. Ando Y. (2007), Handbook of Acoustics, Thomas Rossing, Editor, Springer-Verlag, New York Chapter 10.

3. BARRon M. (1971), The subjective effects of first reflections in concert halls - the need for lateral reflections, Journal of Sound and Vibration, 15, 475-494.

4. BARRon M. (2001), Late lateral energy fractions and the envelopment question in concert halls, Applied Acoustics, 62, 185-202.

5. Barron M., LeE L-J. (1988), Energy relations in concert auditoria I, Journal of the Acoustical Society of America, 84, 618-628.

6. Barron M., Marshall A.H. (1981), Spatial impression due to early lateral reflections in concert halls. The derivation of a physical measure, Journal of Sound and Vibration, 77, 211-232.

7. Beranek L.L. (1962), Music, Acoustics and Architecture, John Wiley \& Sons, New York.

8. BeraneK L.L. (1992), Concert hall acoustics, The Journal of the Acoustical Society of America, 92, 139.

9. Blauert J., Lindemann W. (1986a), Auditory spaciousness: Some further psychoacoustic analyses, The Journal of the Acoustical Society of America, 80, 533542 .

10. Blauert J., Lindemann W. (1986b), Supplementary psychoacoustical results on auditory spaciousness, Acustica, 59, 292-293.

11. Bradley J.S. (1994), Comparison of concert hall measurements of spatial impression, Journal of the Acoustical Society of America, 96, 3525-3535.

12. Bradley J.S. (1996), Some effects of orchestra shells, Journal of the Acoustical Society of America, 100, 889898.

13. BRADLEy J.S. (2011), Review of objective room acoustics measures and future needs, Applied Acoustics, 72, 713-720. 
14. Bradley J.S., Reich R.D., Norcross S.G. (2000), On the combined effects of early- and late-arriving sound on spatial impression in concert halls, Journal of the Acoustical Society of America, 108, 651-661.

15. Bradley J.S., Soulodre G.A. (1995a), The influence of late-arriving energy on spatial impression, Journal of the Acoustical Society of America, 97, 22632291.

16. Bradley J.S., Soulodre G.A. (1995b), Objective measures of listener envelopment, Journal of the Acoustical Society of America, 98, 2590-2597.

17. Cox T.J., Davies J., LAm Y.W. (1993), The sensitivity of listeners to early sound field changes in auditoria, Acustica, 79, 27-41.

18. CREMER L. (1989), Early reflections in some modern concert halls, Journal of the Acoustical Society of America, 85, 1213-1225.

19. Damaske P., Ando Y. (1972), Inter aural cross correlation for multichannel loudspeaker reproduction, Acustica, 27, 232-238.

20. De Vries D., Hulsebos E.M., BaAn J. (2001), Spatial fluctuations in measures for spaciousness, Journal of the Acoustical Society of America, 110, 947-954.

21. Evjen P., Bradley J.S., Norcross S.G. (2001), The effect of late reflections from above and behind on listener envelopment, Applied Acoustics, 62, 137-153.

22. GAdE A.C. (1989), An acoustical survey of eleven European concert halls - a basis for discussion of halls in Denmark, The Acoustics Laboratory, Tech. Univ. of Denmark, [Report No.44].

23. Girón S., Galindo M., Zamarreño T. (2008), Distribution of lateral acoustic energy in Mudejar-Gothic churches, Journal of Sound and Vibration, 315, 11251142 .

24. Girón S., Zamarreño T., Galindo M. (2010), Experimental study of support parameters in auditorium and proscenium stages, Acta Acustica united with Acustica, 96, 1026-1041.

25. Hidaka T., Beranek L.L., Okano T. (1995), Interaural cross-correlation, lateral fraction, and low- and high-frequency sound levels as measures of acoustical quality in concert halls, Journal of the Acoustical Society of America, 98, 988-1007.

26. International Organization For Standardization ISO 3382-1:2009(E), (2009), Acoustics-Measurement of room acoustic parameters, part 1: Performance rooms, Geneva, Switzerland.
27. Kleiner M. (1989), A new way of measuring the lateral energy fractions, Applied Acoustics, 27, 321-327.

28. León A.L., Sendra J.J., NAvarro J., ZamarreÑO T. (2007), Acoustics and restoration in theatres of Andalucia [in Spanish: Acústica y Rehabilitación en Teatros de Andalucía], Secretariado de Publicaciones de la Universidad de Sevilla, Sevilla.

29. Marshall A.H. (1967), A note on the importance of room cross-section in concert halls, Journal of Sound and Vibration, 5, 100-112.

30. Marshall A.H. (1968), Levels of reflection masking in concert halls, Journal of Sound and Vibration, 7, $116-118$.

31. MIREM (Mapa Informatizado de Recintos Escénicos y Musicales; Fundación Autor, Sociedad General de Autores y Editores) http://www.artenetsgae.com/mire/index.htm [Digital Scenic and Musical Enclosure Map, Author Foundation] (Accessed September 2012, currently only in Spanish).

32. Morimoto M., Iida K., Sakagami K. (2001), The role of reflections from behind the listener in spatial impression, Applied Acoustics, 62, 109-124.

33. Morimoto M., Nakagawa, K. Iida K. (2008), The relation between spatial impression and the law of the first wavefront, Applied Acoustics, 69, 132-140.

34. Okano T., Beranek L.L., Hidaka T. (1998), Relations among interaural cross-correlation coefficient (IACCE), lateral fraction (LFE), and apparent source width $(A S W)$ in concert halls, Journal of the Acoustical Society of America, 104, 255-265.

35. Peutz V.M.A. (1971), Articulation loss of consonants as a criterion for speech transmission in a room, Journal of the Audio Engineering Society, 19, 915-919.

36. Sabine W.C. (1993), Collected Papers on Acoustics. (Cambridge: Harvard University Press), Reprinted by Acoustical Society of America, New York.

37. Schroeder M.R., Atal B.S., Sessler G.M., West J.E. (1966), Acoustical measurements in the Philharmonic Hall (New York), Journal of the Acoustical Society of America, 40, 434-440.

38. Soeta Y., Nakagawa S., Tonolke M., Ando Y. (2002), Magnetoencephalographic responses corresponding to individual subjective preference of sound fields, Journal of Sound and Vibration, 258, 419-428.

39. West J.E. (1966), Possible subjective significance of the ratio of height to width of concert halls, Journal of the Acoustical Society of America, 40, 1245. 